\title{
LA TELEFONÍA MÓVIL CELULAR EN ESPAÑA: POLÍTICAS DE GOBIERNO Y DE EMPRESAS. EL CASO DE INDELEC, 1984-2003
}

\author{
MOBILE CELLULAR TELEPHONY IN SPAIN: GOVERNMENT \\ AND BUSINESS POLICIES. THE CASE OF INDELEC, 1984-2003 \\ Ángel Calvo* \\ Universidad de Barcelona, España
}

\begin{abstract}
RESUMEN: Este artículo aborda la forja y resultados de una alianza entre la operadora monopolista del servicio telefónico, el capital multinacional y una administración autonómica resuelta a recuperar tejido industrial gracias a la introducción de una tecnología avanzada de las telecomunicaciones en un territorio (País Vasco) castigado por la depresión durante y tras la reconversión industrial de los primeros años de la década de 1980. Pretende dilucidar a través de un estudio de caso si se dieron elementos diferenciales respecto a la estrategia seguida por las multinacionales en otras ocasiones. La metodología utilizada consiste en el trazado del marco contextual de los hechos centrales y en el relato de la concepción, nacimiento y trayectoria de la empresa señalada. El trabajo sigue la huella de estudios sectoriales de carácter agregado, publicados hace un decenio, a los que les añade la perspectiva de la historia empresarial. En un segundo eje, adopta la perspectiva comparada para contrastar diversas situaciones y circunstancias estudiadas. Afloran asimismo otros aspectos fundamentales, como el engarce de la actividad reguladora y de las políticas industriales en sus diferentes niveles de elaboración y ejecución.
\end{abstract}

PALABRAS CLAVE: INDELEC, telefonía móvil, radioteléfono, empresas, política industrial, alianzas. CÓDIGOS JEL: NO0, L12, L20, L50

\begin{abstract}
This article deals with the forge and results of an alliance between the monopoly operator of the telephone service, the multinational capital and an autonomous administration determined to recover industrial fabric thanks to the introduction of an advanced technology of telecommunications in a territory (Basque Country) punished by the depression during and after the industrial reconversion of the first years of the decade of 1980. It seeks to elucidate through a case study possible differential elements regarding the strategy followed by the multinationals in other occasions. The methodology used consists in the drawing of the contextual framework of the central facts and in the story of the conception, birth and trajectory of the company indicated. The work follows the trail of sectoral studies of an aggregate nature, published a decade ago, to which the perspective of business history adds. In a second axis, it adopts the comparative perspective to contrast different situations and circumstances studied. Other fundamental aspects also emerge, such as the link between regulatory activity and industrial policies at different levels of development and execution.
\end{abstract}

KEYWORDS: INDELEC, mobile telephony, radiotelephone, companies, industrial policy, alliances.

JEL CODES: NOO, L12, L20, L50

* Correspondencia a: Ángel Calvo. Departament d'Història Econòmica, Institucions, Política i Economia Mundial (Universitat de Barcelona), Facultat d'Economia i Empresa Edifici Principal, Torre 2-4. ${ }^{a}$ planta. Av. Diagonal, 690 (08034 Barcelona) - angel.calvo@ub.edu - https//orcid.org/0000-0002-1370-9970

Cómo citar: Calvo, Ángel (2020). "La telefonía móvil celular en España: políticas de gobierno y de empresas. El caso de INDELEC, 1984-2003»; Historia Contemporánea, 62, 219-262. (https://doi.org/10.1387/hc.20741).

Recibido: 18 julio, 2018; aceptado: 17 enero, 2019.

ISSN 1130-2402 - elSSN 2340-0277 / ㄷ 2020 UPV/EHU

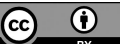

Esta obra está bajo una licencia

Creative Commons Atribución 4.0 Internacional 


\section{Introducción}

El artículo ahonda en los orígenes y primer desarrollo de la telefonía móvil en España, desde los primeros «teléfonos para coche» de Philips o Ericsson y los primeros teléfonos de bolsillo - el Poctel 2000 - hasta la época de afianzamiento y expansión mundial, momentáneamente cercenada por el estallido de la burbuja punto.com, cuyos impulsores tecnológicos fueron los microprocesadores, en especial el Intel 8086, y el sistema de intercambio de datos de alta velocidad. De forma más específica, el estudio centra su atención en la forja y resultados de una alianza entre la operadora monopolista del servicio telefónico (Telefónica), el capital multinacional y una administración autonómica resuelta a recuperar tejido industrial gracias a la introducción de una tecnología avanzada de las telecomunicaciones en el País Vasco, un territorio castigado por la depresión durante y tras la reconversión industrial de los primeros años de la década de 1980.

La metodología utilizada en el estudio consiste en el trazado del marco contextual de los hechos centrales y en el relato de los mismos, es decir, la concepción, nacimiento y trayectoria de la empresa INDELEC. El segundo eje pasa por la perspectiva comparada para enriquecer las diversas situaciones y circunstancias estudiadas.

En este artículo se contrastan dos hipótesis interrelacionadas. La primera pretende probar si las políticas de atracción de tecnología avanzada desarrollada por las multinacionales del sector contribuyen a superar atrasos crónicos. La segunda persigue determinar si existieron elementos diferenciales respecto a la estrategia seguida por las multinacionales en otras ocasiones.

El artículo sigue la huella de estudios sectoriales de carácter agregado, publicados un decenio atrás ${ }^{1}$. A ellos les añade la perspectiva de la historia empresarial, que permite captar la textura de la materia base del sector, es decir de la empresa, a través del análisis de la trayectoria de INDELEC, una firma de radioteléfonos. Afloran asimismo otros aspectos fundamentales, como el engarce de la actividad reguladora y de las políticas industriales a distintos niveles de elaboración y ejecución.

Causa cierta desazón constatar que España se asoma con dificultad a las estadísticas. Sacar a luz prácticamente de la nada un caso sobrada-

\footnotetext{
${ }^{1}$ López y Valdaliso, 2011, pp. 317-336; Valdaliso y López, 2008, p. 5.
} 
mente citado pero poco estudiado ha sido posible gracias al uso de fuentes primarias empresariales y de diversas administraciones públicas involucradas, así como de testimonios orales de personas con grados de responsabilidad diversos en los episodios descritos. Entre ellas destacan por su excepcionalidad las de INDELEC y las de Telefónica, uno de los protagonistas del relato, ya que, dentro de la parquedad de información general, aportan valiosos detalles sobre la gestación de la empresa que sirve de estudio de caso. Sobresalen asimismo las del Parlamento Vasco, que proporcionan pormenores sobre el entorno político en que se desenvuelve la creación y evolución de INDELEC ${ }^{2}$. El estudio aborda cuestiones de importancia en la trayectoria de la empresa en sus vertientes productiva, inversora o financiera pero se centra en el papel desempeñado por las instituciones del país, tanto las estatales como las autonómicas en la estructura accionarial.

El trabajo se estructura en tres grandes apartados, enmarcados por una introducción aclaratoria y unas conclusiones. El cuerpo central empieza trazando un cuadro general de la expansión de las comunicaciones inalámbricas, para pasar a analizar la imbricación de las políticas industriales, el desarrollo regional y la estrategia de las multinacionales, la conjunción de iniciativas en torno a una nueva empresa conjunta - INDELEC - localizada en el País Vasco y el relevo de los líderes tecnológicos en la misma.

Se impone aclarar algunas cuestiones preliminares. La primera alude a una definición terminológica y se refiere a las tecnologías de la información y la comunicación (TICs), sector en el que se incluye la radio, objeto de investigación en este artículo. Las TICs responden a la condición de tecnología de uso general (General Purpose Technology), calificada así por los economistas evolucionistas, entre ellos por Paul David, por considerar que afectan al conjunto del sistema económico ${ }^{3}$.

La segunda precisión tiene que ver con el carácter estratégico del sector, que reclama una regulación del mismo. Tal función corresponde en

${ }^{2}$ Un Informe anual de INDELEC, cedido por Francisco Lacha, resulta un material impagable. Ni en la Biblioteca Nacional ni en otras instituciones que suelen ser depositarias de materiales imprescindibles para el estudio de las empresas se guardan Memorias anuales o informes financieros de la empresa. La agencia de información Axesor, hacia 19951996, clasificaba a INDELEC entre las empresas con un capital superior a los $100.000 €$, un empleo entre 11-50 y ventas del orden de 3 millones de $€$.

${ }^{3}$ Liao, 2016, pp. 10-25. 
primer lugar a la Unión Internacional de Telecomunicaciones, que define los estándares en cada generación de telefonía móvil. A su vez, las organizaciones supranacionales - UE en el caso que nos corresponde- determinan las directrices al respecto y dejan en manos de los gobiernos de los estados nacionales la definición precisa de los sistemas ${ }^{4}$. Conviene recalcar que el estudio aborda los orígenes de la telefonía móvil en España desde la vertiente de la industria de equipos y no del servicio o de la tecnología, foco preferente de atención en la bibliografia (Pérez Sanjuán, coord., 2006; Vergara y Huidobro, 2016, pp. 142-145; Calzada y Estruch, 2011, pp. 39-69; Calvo, 2019, pendiente). Este aspecto supone el primer elemento diferencial del artículo. El segundo se refiere a la naturaleza mixta de la empresa protagonista por tratarse de la inversión conjunta entre el sector público no estatal - un gobierno autonómico- y la empresa, representada por dos multinacionales y una operadora de teléfonos semipública, a punto de perder su privilegio de monopolio e iniciar una etapa de competencia abierta.

La tercera precisión se refiere al marco territorial y a la definición de sus características relacionadas con la temática que nos ocupa. En cuanto al nivel de comunicaciones e información, en 1990, el País Vasco ocupaba una posición muy destacada en el ránking de nivel de TICS en España. En efecto, figuraba en segundo lugar, detrás de Madrid y delante de Cataluña ${ }^{5}$. Las TICs, sector emergente en el País Vasco, encabezaban el pujante cluster de telecomunicaciones, que facturaba entre 100.000150.000 millones de pesetas y ocupaba 6.000 personas $^{6}$.

\section{La expansión de los sistemas de comunicación inalámbrica}

Como señala la Unión Internacional de Telecomunicaciones, en las postrimerías del siglo Xx hemos sido testigos de la extraordinaria expan-

4 Así, por ejemplo, la Directiva 87/372/CEE (conocida como Directiva GSM), aprobada en el año 1987, reservaba la banda de $900 \mathrm{MHz}$ para ser utilizada por los sistemas GSM si bien sucesivas modificaciones abrieron estas bandas a otros sistemas.

5 Corral, 1992, p. 179.

${ }^{6}$ Comparecencia del Director General de la SPRI, al objeto de que informe en relación con el reciente Congreso Internacional de Telecomunicaciones, expediente 05\06103\03\0023, Comisión, V Leg.-Comisión de Industria y Agricultura, 25-6-1996. 
sión de los sistemas de comunicaciones inalámbricas ${ }^{7}$.Esta tecnología permitió la comunicación multimodal desde un lugar a otro cualquiera siempre que existiera la infraestructura adecuada y se ha difundido a gran velocidad $^{8}$. Lugares alejados de la civilización o de geografía hostil al despliegue de líneas de cobre se han incorporado a la comunicación e igual ha sucedido con segmentos de población tradicionalmente al margen, sin lograr abatir por completo las barreras de la pobreza y de la desigualdad por género, como reconoce The Mobile Gender Gap Report de 2018.

La implantación de esta tecnología por países siguió derroteros diferentes según el nivel de desarrollo, las tecnologías disponibles y las políticas adoptadas. Las naciones resolvieron con fórmulas diferenciadas la necesaria disponibilidad de redes y equipos de usuarios. Por limitarnos a un caso de un país que en este estudio va a ser referencia frecuente, Francia, sin esperar al desarrollo de la radiotelefonía digital, decidió satisfacer las necesidades de su atrasado mercado con una nueva red de tecnología analógica. La instalación y operación de dicha red fue encomendada a la Compagnie Générale des Eaux, que se basó en inversiones de fondos propios y en la tecnología de la finlandesa Nokia y de la francesa Alcatel. Frente a otros dos competidores - Société Lyonnaise des Eaux y el grupo Bouygues - , se consideró al candidato seleccionado como mejor pertrechado para proporcionar una cobertura máxima y rápida del territorio metropolitano, al tiempo que garantizaba la mejor capacidad futura de la industria francesa en el sector ${ }^{9}$.

Más específicamente, la disparidad de la propagación de las radiocomunicaciones con móviles por los grandes países industrializados queda recogida a satisfacción en el Gráfico 1 y en el Anexo 1. El primero habla a las claras de la preponderancia estadounidense y del consiguiente atraso europeo en relación al país líder, como también de las diferencias dentro de Europa, zona en la que los países nórdicos ocupan la posición más destacada ${ }^{10}$. Ciertamente, no todos los servicios presentaban perfiles simila-

7 Oficina de Radiocomunicaciones de la Unión Internacional de Telecomunicaciones 2010, p. 7.

8 Castells et al.2009, p. 1.

9 Assemblée Nationale, Réponse du Ministère des PTT à la Question N. ${ }^{\circ} 35.240$ de M. Schreiner Bernard (Socialiste-Yvelines), Journal Officiel, 11/1/1988, p. 101, y 14/3/1988, p. 1.194 .

10 En agosto de 1992, las tasas de penetración del radioteléfono eran de más de 22 por 1.000 habitantes en el Reino Unido, de 9 en Alemania y de más de 6 en Francia: Réalités industrielles: une série des Annales des mines, abril de 1993, p. 66. 
res en el nivel de penetración por los países, como refleja el Gráfico 1 y habrá ocasión de examinar más adelante para el servicio mensafónico ${ }^{11}$.

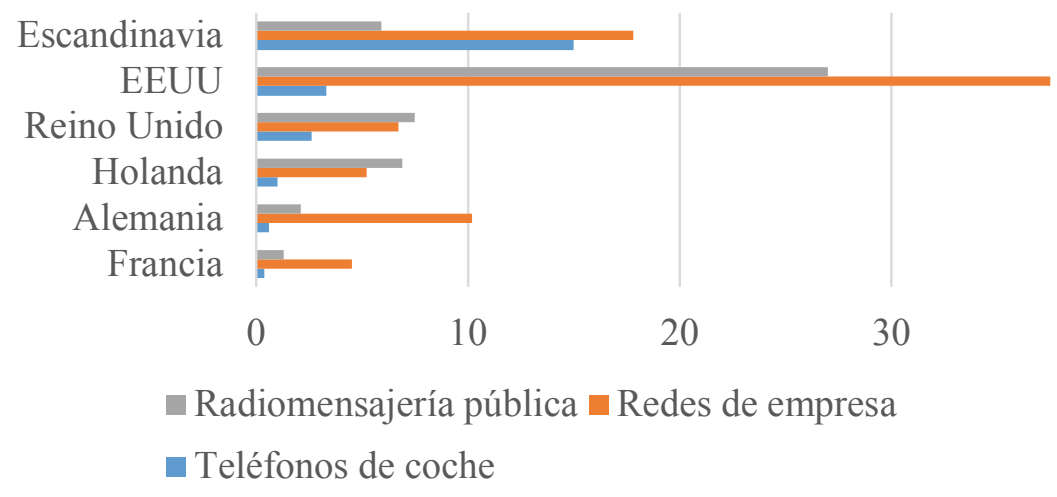

\section{Gráfico 1}

Radiocomunicaciones con móviles en un grupo de países industrializados hacia 1987. Tasas de penetración/1.000 h

Fuente: elaboración propia a partir de Ministère des PTT (1987).

Nota: Teléfonos de coche y redes de empresa: n. de móviles/1.000 h.; radiomensajería pública: número de receptores//1.000 h.

En su evolución, el uso del radioteléfono se extendió en las empresas de servicios y en algunos servicios públicos como el taxi, que necesitaban atender puntualmente los requerimientos de la clientela ${ }^{12}$. Más específica-

11 A escala regional, se conocen cifras de servicios móviles, considerados como servicios de valor añadido; en Cataluña, por ejemplo, había unos 25.000 usuarios hacia 1991: Recober et al. (1991).

12 Ayres 2014, p. 157. Algunos equipos eran primordialmente teléfonos portátiles adaptables a vehículos, como sucedía con el INDELEC 6222: $A B C, 23 / 7 / 1991$. Philips publicitaba su teléfono para coche TMA PHILIPS AP 4000 como una tecnología avanzada, con una amplia gama de accesorios y un servicio gratuito de mantenimiento durante tres años en sus puntos distribuidos por toda España: La Vanguardia, 3 de junio de 1987 y 27 de diciembre de 1989. Durante las fiestas patronales de Barcelona, Butano organizó una numerosa flota de vehículos equipados con radio-teléfono para atender con rapidez las urgencias o averías: La Vanguardia, 24 de septiembre de 1967. Además de los teléfonos para coche, existieron también los de autobús teléfonos sobre ruedas, en suma: Direction 
mente, en Cataluña se utilizaba la radiotelefonía en grupo cerrado como servicio interno en sectores económicos u organismos oficiales con importante necesidad de comunicación con el personal esparcido por el territorio ${ }^{13}$.

Cabe señalar en este punto que la radiotelefonía no se reduce a las comunicaciones móviles públicas y que, incluso limitándola exclusivamente a la provisión de servicios de telecomunicaciones basados en la transmisión de la voz, las redes destinadas a prestar tales servicios pueden ser públicas o privadas. Esta distinción es transcendental en aspectos como la tecnología necesaria, la inversión requerida o la regulación implicada, entre otros.

La radiotelefonía móvil cobró un impulso importante con el desarrollo de técnicas que mejoraban sensiblemente el uso del siempre escaso espectro radioeléctrico, entre ellas las nuevas modulaciones digitales, la celularización, la codificación y el acceso a canal. Por parte de la oferta, las inversiones de los proveedores de red en sistemas móviles como el TMA o el Telepunto y la decisión de la Comunidad Europea de desarrollar el sistema móvil digital paneuropeo GSM y un sistema paneuropeo de radiomensajería ERMES (European Radio Message System) junto con una excelente respuesta por parte de la demanda constituyeron los factores decisivos para el crecimiento de la telefonía móvil ${ }^{14}$. La radiotelefonía móvil privada tendió a un nuevo concepto - las comunicaciones o telefonía personal - a través de dos líneas de desarrollo con sistemas trunking para grandes extensiones y de corto alcance con teléfonos digitales sin hilos, las centralitas digitales con extensiones sin hilos y las redes de área local vía radio.

El mercado estaba dominado por un reducido grupo de fabricantes, formado por cuatro empresas europeas - Ericsson (Suecia), Phillips (Holanda), Nokia (Finlandia) y Siemens (Alemania) - , una estadounidense - Motorola - , una canadiense - Novatel-y dos japonesas - Mitsu-

des télécommunications des réseaux extérieurs 1983; Régie autonome des transports parisiens 1984. El Poctel 2000 era un terminal móvil UHF duplex diseñado para el sistema Radiocom 2000 y fabricado à partir de 1987 por ALCATEL: Electrical Communication, 60-61, 1986, p. 327; Le Monde, 26/7/1988.

13 Recober et al. (1991).

${ }^{14}$ La superioridad del estándar ERMES radicaba en su capacidad para permitir la itinerancia en un área geográfica amplia y en su mayor potencial de transmisión de datos respecto al POCSAG: Wireless Cellular Monthly Newsletter, 1, 3, octubre de 1991, p. 19. 
bishi y NEC - . En su mayoría, estos fabricantes de elementos de red y estaciones base competían también en el mercado de terminales. En España, los proveedores de estos equipos eran Intelsa (Ericsson), Indelec (Phillips) y Motorola.

Por su parte, la industria producía terminales de usuario especializados en servicios concretos como las centralitas y sistemas de interconexión, los teléfonos, el fax, los terminales TMA y el videotex ${ }^{15}$. Rareza absoluta en el panorama español de la telefonía móvil fue Vitelcom Mobile Technology SA (2001), emplazada en el Parque Tecnológico de Andalucía. Absorbió know-how de INDELEC - mano de obra cualificaday llegó a producir cinco millones de terminales al año. Su dependencia total de Telefónica entrañó el despegue de la empresa y su tumba, ya que la caída de la demanda de la operadora le propinó un golpe mortal ${ }^{16}$.

\section{Política industrial, desarrollo regional y empresas multinacionales}

Durante años, el sector de las telecomunicaciones fue considerado en la Unión Europea un sector excluido, sujeto solamente a normas en materias generales. En 1984, la Comisión de las Comunidades Europeas inició el desarrollo de la política comunitaria en telecomunicaciones y a partir de ese momento, llevó a cabo una amplia labor reglamentadora en el sector, con el objetivo final de lograr un mercado unificado. En ese año creó la Task Force de las tecnologías de la información y de las telecomunicaciones y elaboró los planteamientos estratégicos esenciales de su política: creación de un mercado comunitario; reducción de las incertidumbres de los operadores y fabricantes; mejora de la situación de la tecnología punta

15 Martí-Recober et al., 1991. España, con su servicio denominado IBERTEX, fue a la zaga del servicio Prestel del Reino Unido (1979) y del videotex francés, soportado en una red de gran capacidad potencial y servido a través del terminal Minitel, muy sencillo y barato. A comienzos de la década de 1990 , se situaba a gran distancia de Francia, que tenía una capacidad 30 veces mayor en terminales, 50 veces en centros de servicio y 100 veces en horas al mes: Fernández y González, 1992, pp. 3-4.

${ }_{16}$ El Economista, 3/03/2007; Entrevista del autor a José Miguel de Diego Rodrigo, 11 de marzo de 2019. Vitelcom fue calificado de «gigante con pies de barro»: Sur, 26 de noviembre de 2017. Con motivo de los Juegos Olímpicos de Barcelona, se instalaron 2.050 terminales y equipos de radiotelefonía de grupo cerrado; algunos de los terminales fueron adjudicados a INDELEC pero acontecimientos excepcionales no podían ser una base firme para garantizar a largo plazo la supervivencia: VV.AA. 1996, p. 296; Grau, 1992, p. 63. 
y cohesión comunitaria a través del fomento de la modernización de las redes y de los servicios avanzados en las regiones más desfavorecidas. Estos planteamientos, materializados en actuaciones concretas, fueron asumidos después en el Libro Verde para el establecimiento del Mercado Común de las Telecomunicaciones de junio de 1987. Los agentes del sector -instituciones comunitarias y de los Estados miembros, operadoras, fabricantes y asociaciones de usuarios - forjaron unas grandes líneas generales. Estas pasaban por la apertura sin restricciones del mercado de equipos terminales, sujeta a los procedimientos de homologación; el mantenimiento de los derechos especiales de las Administraciones de telecomunicaciones en lo relativo a la oferta y explotación de la infraestructura de red; la apertura sustancial de los servicios de telecomunicación a la competencia, con la salvaguarda de los objetivos de servicios públicos mediante el mantenimiento de derechos especiales o exclusivos para la prestación de un número determinado de servicios básicos; la definición clara de las exigencias generales para la utilización de la red, impuestas por las administraciones de telecomunicaciones; la definición de la oferta de red abierta (ONP); la separación entre actividades de reglamentación y explotación de las Administraciones comunitarias; el seguimiento de las actividades de reglamentación y de explotación de las Administraciones y los operadores públicos y privados y, finalmente, la aplicación de una política comercial común a las telecomunicaciones. Las líneas generales se materializaron en un conjunto normativo, que abogaba por el desarrollo del mercado común de los servicios y equipos de telecomunicación. Además, se fijaba una categoría de servicios reservados - los servicios de telefonía vocal - que, al generar el grueso de los ingresos (más del 85 por ciento de total) garantizaba la viabilidad financiera de las operadoras. Finalmente, establecía la separación entre la operación de los servicios y las actividades de regulación. Para lo que interesa aquí, la directriz central abolía «los derechos exclusivos o especiales para el suministro de servicios de telecomunicaciones» en todos los servicios ajenos a la telefonía vocal, entre ellos la radiotelefonía móvil y la radiomensajería ${ }^{17}$.

17 Resolución 88/C 257/01 del Consejo (junio/1988) sobre el desarrollo del mercado común de los servicios y equipos de telecomunicación hasta 1992; Directiva 90/388/CEE de la Comisión (junio /1990) relativa a la competencia en los mercados de servicios de telecomunicaciones, que abolía «los derechos exclusivos o especiales para el suministro de servicios de telecomunicaciones» en todos los servicios ajenos a la telefonía vocal - télex, radiotelefonía móvil, radiomensajería y comunicaciones por satélite: Silván, 1992, pp. 1-9. 
Igualmente a nivel territorial, cabe definir el marco normativo e institucional en el que se inscribe la creación de INDELEC, no sin dejar de subrayar de nuevo que el estudio se centra en la industria de equipos y no en el servicio.

El Gobierno vasco ejerció un papel de intermediario en el sector de las telecomunicaciones a través de presiones políticas encaminadas por partida doble a la creación directa de empresas y al fomento de ventajas comparativas para la comunidad autónoma. La cuenta de ayudas del gobierno autonómico por el conjunto de iniciativas se cifró en 158 millones de euros (26.400 millones de pesetas) en 1996. A lo largo de la década de 1980 y en los primeros años de la siguiente, el Ejecutivo vasco tomó diversas iniciativas para la informatización de la administración regional, extendió las redes implantadas a otras zonas de la región y creó una operadora de telecomunicaciones regional. En el año 1982, creó la Sociedad Informática del Gobierno Vasco (EJIE), a la que encomendó la implantación de la informática en la administración regional, la interconexión de las universidades de la región y el impulso de una red de microondas para la transmisión de datos. A esta le siguió la Red Oficial de Comunicaciones del Gobierno, encargada de prestar los servicios de transporte y difusión de los programas de las emisoras de radio y televisión.

El broche final llegó con el «Plan Europa 93», que contaba con el apoyo financiero de la Unión Europea. Su objetivo era desarrollar una infraestructura pública de fibra óptica y el servicio de radio y televisión pública así como servicios ofimáticos y telemáticos de la administración vasca. Del inicio de la década (1993) es la Sociedad de Telecomunicaciones del Gobierno vasco, EUSKALNET, que se convirtió en el agente instrumental de las actuaciones del Gobierno en el ámbito de las telecomunicaciones y logró hacerse con una cuota sustancial - a mediados de 1999 más de la cuarta parte - del mercado de la telefonía en la región. Instituciones diferenciadas fueron destinadas a actuar en el sector con una distinción clara entre la esfera pública - servicios de la administración vasca y las relaciones con los ciudadanos - y la privada - servicios en empresas y en hogares - . Las acciones a desarrollar en la esfera pública, englobadas en el concepto "promoción de la sociedad de la información», abarcaban tres ámbitos, a saber, el Núcleo de Telecomunicaciones de Euskadi, el Plan de Ciencia y Tecnología de Euskadi 1997-2000 con su renovación para el periodo 2001-2004, y EUSKALTEL como soporte de nuevos y baratos servicios de telecomunicaciones en la región. Significativo para lo que aquí se viene narrando, en 1997 Ericsson suministró red inteligente 
a EUSKALTEL junto a un completo paquete de servicios llave en mano. No faltaron contactos con el exterior para potenciar acciones en la creación de una red de telecomunicaciones del País Vasco ${ }^{18}$.

En octubre de 1995, el Departamento de Industria del Ejecutivo vasco realizó un «Diagnóstico de Posicionamiento Competitivo y de Identificación y Priorización de Opciones» sobre el conjunto de empresas de productos y servicios de telecomunicaciones en la región. Con esta iniciativa pretendía avanzar en la creación de un «Núcleo de Telecomunicaciones de Euskadi», cuya implantación aseguró casi un año después, a través de dos organismos: la Asociación de Industrias de Telecomunicaciones de Euskadi y el Consejo Asesor del Núcleo. Por su parte, el segundo ámbito en el que desarrolló competencias fue el Plan de Ciencia y Tecnología 1997-2000 ${ }^{19}$. El Gobierno vasco impulsó una demarcación única de cable en su territorio, posibilidad recogida en la Ley de Telecomunicaciones por Cable, y explotó las posibilidades de participar en las instituciones nacionales y de la Unión Europea que debatían los temas del sector de las telecomunicaciones. El gobierno autonómico vio en la liberalización una ventana abierta a mayores prerrogativas descentralizadas y buscó involucrarse como promotor y consumidor de nuevos servicios (Plan de Sistemas de la Información y Telecomunicaciones 1997-2000), la promoción de la sociedad de la información y la convergencia de intereses del sector.

18 En 1994, Gary Hart, senador de los EE.UU., junto a representantes de las empresas US West y Time Warner, se entrevistaron con el presidente del Ejecutivo vasco, J. A. Ardanza, para explorar la inversión de las mismas en una posible red: Gobierno Vasco, 2004, p. 428. La parte norteamericana, en la que figuraba la vicepresidenta de US West, Maureen O'Ryan, miembro además del gabinete económico internacional del Gobierno de los Estados Unidos y asesora en política de inversiones americanas en el extranjero del vicepresidente Al Gore, cifró el plan de inversiones en unos 50.000 millones de ptas. La propuesta de inversión obedecía a las características del proyecto - buenas expectativas económicas - y a factores inherentes a la comunidad autónoma - dotación de infraestructura comunicaciones - . US West era una de las propietarias de Time Warner - el mayor grupo de comunicación del mundo- y socia de la operadora de cable TCI: El País, 21 de mayo de 1994. EUSKALTEL adoptó la solución Packet Backbone Network (PBN) de Ericsson para ampliar su red troncal de datos: Ericsson, Press release, 21 de julio de 2003.

${ }^{19}$ La Asociación de Telecomunicaciones de Euskadi, que tenía su origen en la Asociación de Industrias Electrónicas del País Vasco, pasó a denominarse Asociación de Industrias de las Tecnologías Electrónicas y de la Información del País Vasco (GAIA). Esta asociación tenía como misión la coordinación y puesta en marcha de proyectos de interés para el conjunto de empresas, entre ellos la inversión en investigación y desarrollo, y la gestión de la actividad diaria del «Núcleo de Telecomunicaciones»: Gil, 2002, pp. 156-163; véase también López García y Valdaliso, 2011,pp. 317-336. 
Como señala la Comisión Europea, el País Vasco ha sido tradicionalmente una economía de base vigorosamente industrial y que ha ejercido una cierta atracción para el capital extranjero, aspecto que nos lleva a la cuestión central del relato. En otras palabras, la empresa clave sobre la que vamos a centrar la atención cobra un relieve significativo pero no predominante en la actividad empresarial ${ }^{20}$. Es el fruto de la confluencia entre la política industrial de impulso ejercida por el gobierno autonómico, el papel motor de la empresa clave de las telecomunicaciones en España - la Compañía Telefónica Nacional de España, CTNE, o sencillamente Telefónica - y la estrategia de expansión de las multinacionales.

En el País Vasco, la política industrial de incentivos e impulso al incremento de la competitividad y productividad empresarial se plasmó en la creación de instrumentos institucionales, como la Sociedad para Promoción y Reconversión Industrial (SPRI) y los Parques tecnológicos, con procesos de clusterización pioneros en los sectores más determinantes de la economía vasca desde principios de los años 90, entre ellos las TICs.

Queda claro que el protagonismo le corresponde a la administración autonómica pero no hay que olvidar la intervención normativa y financiera del Gobierno central, empezando por la ley de reconversión industrial de 1984 y continuando con los Planes Electrónicos e Informáticos Nacionales, junto a los programas de impulso a la $\mathrm{I}+\mathrm{D}^{21}$.

La Sociedad para la Promoción y Reconversión Industrial, S.A. (SPRI) se constituyó el 21 de septiembre de 1981 por aplicación de la Ley 5/1981, de 10 de junio, como instrumento complementario de promoción y reconversión de la industria vasca y, de forma prioritaria, de

${ }^{20}$ La inversión extranjera directa en el País Vasco en el ejercicio de 1.990 se elevó a 51.852 millones de ptas. Durante el periodo 1985-1997, esta comunidad autónoma (4\% del total) ocupaba una posición muy modesta en la distribución regional de la IED en España, a gran distancia de la Comunidad de Madrid (44\%) y de Cataluña (29\%): Díaz 2001), p. 10; en el año 2001, la IED en el País Vasco alcanzó los 1.981 millones de euros, el $4.11 \%$ de la habida en el conjunto de España, y procedía de EEUU de América, Francia, Luxemburgo, Alemania, Reino Unido y Países Bajos: Gobierno Vasco, 2004 p. 370.

21 López y Valdaliso, 2011; Valdaliso y López, 2008), pp. 1-20; VVAA, 2010, pp. 38-42. Sin espacio para entrar en detalles, señalamos el entramado de relaciones que generaba la participación en encuentros internacionales. Es el caso de las conversaciones de numerosas multinacionales mantenidas con empresas del País Vasco durante el Congreso Internacional de Telecomunicaciones de 1996: Comparecencia del Director General de la SPRI, a petición de la Comisión al objeto de que informe en relación con el reciente

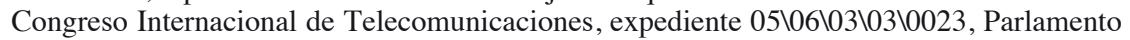
vasco, Comisión, V Leg.-Comisión de Industria y Agricultura, 25.06.1996. 
defensa y creación de puestos de trabajo ${ }^{22}$. La Ley facultaba a esta sociedad a participar en el capital de empresas de particular interés, previa autorización del Gobierno vasco y en las condiciones a estipular en cada caso. A finales de 1993, la SPRI intervenía en cincuenta sociedades, en el grueso de las mismas, es decir en 44, de forma mayoritaria. De las participadas mayoritariamente, la tercera parte estaban endeudadas con entidades financieras, mientras que dos de las participadas minoritariamente (INDELEC y Urnieta Lantzen) compartían tal situación. Finalmente, una estaba financiada directamente por la SPRI -el Centro de Empresas de Zamudio- ${ }^{23}$. Detengámonos un momento en el papel desempeñado por la SPRI en sus distintas facetas de actuación ${ }^{24}$. Desde su creación hasta 1995, la SPRI concedió diferentes líneas de préstamos por importe de 18.340 millones de pesetas, el grueso de los cuales correspondió a los préstamos de reconversión, concedidos en el cuatrienio 1981-1984 y orientados al saneamiento y reconversión de empresas en situaciones críticas. A partir de 1984 y hasta 1986 fueron sustituidos por los préstamos de promoción, destinados a apoyar la creación de nuevas empresas o a acometer proyectos de interés tecnológico en las ya existentes.

Les sucedieron durante el periodo 1987-1992 los préstamos de inversión innovadora, dirigidos a las Pymes básicamente del sector TICs y con proyectos de inversiones dentro del territorio de la CAPV. Simultáneamente, se lanzaron los préstamos de nuevas iniciativas empresariales, destinados a empresas de nueva creación y a personas físicas que se iniciaran por vez primera en la experiencia empresarial. En 1993 y 1994 se iniciaron dos líneas sucesivas de préstamos de creación de nueva empresa, ambas destinadas a las PYMEC industriales transformadoras - plantilla inferior a 250 trabajadores y recursos propios por debajo de 750 millones de pesetas - , de nueva creación y de alto valor añadido. La diferencia estribaba en la consideración de zonas de desarrollo industrial dentro del ámbito geográfico de seis sociedades SORTU distribuidas por el territorio. Por su

22 Ernst \& Young, 2008, p. 11.

${ }^{23}$ Comparecencia del máximo responsable de la SPRI, a petición de la Comisión, de conformidad con la solicitud formulada por el Sr. Dueñas Crespo, del Grupo Parlamentario Mixto-UA, con objeto de que informe sobre la situación del endeudamiento de las empresas en las que participa con recursos procedentes del presupuesto general de la Comunidad Autónoma Vasca, expediente 04\06\03\03\0035, IV Legislatura, Comisión de Industria y Agricultura, 17 de febrero de 1994.

24 Tribunal Vasco de Cuentas Públicas, 1997. 
parte, se calificó de préstamo a la industria un único préstamo concedido por la SPRI en 1994 a una empresa del sector de transformación de la madera. Finalmente, los préstamos personales (1986 a 1992) iban destinados a personas físicas que se involucraran en un proyecto empresarial englobado dentro de la línea de nuevas iniciativas empresariales (Gráfico 2) ${ }^{25}$.

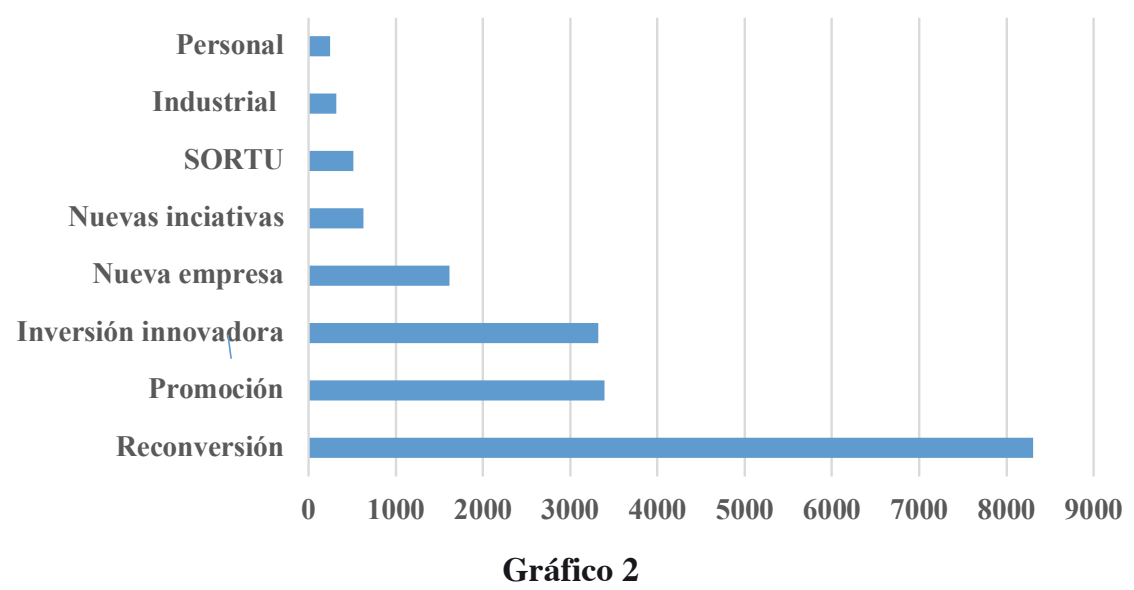

Préstamos concedidos por la SPRI y su estructura, 1981-1985

(millones de pesetas)

Fuente: elaboración a partir de Tribunal Vasco de Cuentas Públicas (1997), p. 40.

Las instituciones vascas se dotaron de instrumentos de apoyo a la inversión de índole distinta. Los pioneros aparecieron en el ámbito del capital riesgo, categoría a la que pertenecía la Sociedad Gestión de Capital Riesgo del País Vasco (SGCPV), creada por la SPRI en 1985 y que administró más de 26.300 millones de ptas. entre 1986 y finales de 2001. A continuación de la SGCRPV surgieron las subvenciones a la inversión, posteriormente completadas por incentivos fiscales. La primera fórmula se plasmó en el Programa de Apoyo a la Inversión (PAI) de 1988, que agrupó todos los programas existentes y dio prioridad a las inversiones con mayor contenido tecnológico, a las PYMES y a sectores o actividades

25 Tribunal Vasco de Cuentas Públicas, 1997. 
de interés preferente. Un trienio después, empezaron a potenciarse las inversiones de gran tamaño y, por tanto, de mayor potencial de arrastre sobre la economía vasca en su conjunto. A esta orientación debieron su existencia la Oficina de Inversiones Estratégicas y el programa GARAPEN, apoyados por la Sociedad de Capital Desarrollo de Euskadi (SOCADE) en la vertiente de capital riesgo. Una serie de resoluciones del parlamento vasco abrieron el camino a nuevos impulsos de política industrial ${ }^{26}$. Fruto de los mismos, el programa GARAPEN fue sustituido en 1996 por el denominado EKIMEN, con idéntica función de atraer grandes inversores, fundamentalmente extranjeros ${ }^{27}$.

El Gobierno vasco ejerció de lobby en la promoción exterior de las empresas de la comunidad autónoma, labor en la que se rodeó de responsables de empresas públicas y representantes de empresas privadas. En este contexto se enmarca un encuentro (marzo de 1994) con un centenar de empresarios franceses organizado por el Consejo Nacional del Patronato Francés y diversas reuniones sectoriales de intercambio sobre industria de telecomunicaciones, energía, agroalimentación, aeronáutica, automovilística y finanzas. El objetivo que se perseguía era afianzar la presencia en el mercado francés, destino de la quinta parte de las exportaciones vascas. Precisamente, en la ocasión INDELEC formó parte de la delegación empresarial, junto a representantes de cuarenta y tres empresas y entidades, entre ellas Gamesa, BBVA, Iberdrola, Mondragón Corporación Cooperativa y la Bolsa de Bilbao ${ }^{28}$.

Respecto a las otras grandes actoras de este relato, las estrategias de localización de las multinacionales obedecen a condiciones del mercado

26 Comunicación del Gobierno sobre el documento «Política Industrial. Marco General de Actuación 1991-1995». (Propuestas de resolución) (05/10.08.00.0001), Boletín Oficial del Parlamento Vasco, 33, 21 de julio de 1995, p. 1.491.

27 Decreto 289/1996, de 17 de diciembre, regulador del Programa Ekimen, de ayudas económicas a las inversiones productivas industriales generadoras de empleo: Boletín Oficial del País Vasco, 246, 6.249, 23/12/1996. Entre 1996-2000, se beneficiaron del programa Ekimen 161 proyectos con un volumen global de inversión de 280.984 millones de pesetas y generaron 10.895 puestos de trabajo directos: El País, 20 de enero de 2000. Socade era el único de los siete fondos integrados en Gestión de Capital Riesgo del Gobierno vasco (SGECR) y centrados en las pymes que estaba orientado a proyectos industriales estratégicos. Socade, entre su constitución en 1993 y hasta 2001, gestionó capitales de más de 30,05 millones, fue accionista del fabricante de aceros especiales GSB, colaboró en diversas reordenaciones de sectores básicos para el tejido industrial de la comunidad autónoma: Cinco Días, 12 de agosto de 2002.

${ }^{28}$ Gobierno vasco, 2004, pp. 380-381. 
mundial muy precisas y que cambian a lo largo del tiempo. Las políticas de atracción de las autoridades de los estados nacionales y de las regiones en sus distintas facetas no garantizan la permanencia en el largo plazo de estas multinacionales, siempre a la búsqueda de condiciones óptimas para el desarrollo de su actividad. Así sucedió con algunas que se instalaron en el País Vasco y nutrieron un rosario de replanteamientos de actividad, entre ellas el gigante cristalero francés Saint-Gobain (Amorebieta) y la química Cabot (Zierbena, con 83 trabajadores) ${ }^{29}$.

Evidentemente, esta dinámica no solo afectaba a las multinacionales, antes bien se extendía a empresas no líderes que buscaban instalarse en suelo vasco. Una de ellas, además, ilustra el proceso complejo que implicaba la inversión directa con beneplácito y ayudas del gobierno autonómico. Hablamos de Grotjhon Precise International, S. A. (GPCISA), un proyecto aprobado por la Oficina de inversiones estratégicas a mediados de diciembre de 1994, sujeto a un informe positivo del departamento internacional de la SPRI y del departamento de Industria y Energía del gobierno autonómico. El consejo de gobierno del 16 de mayo de 1995 aprobó las subvenciones por la inversión y creación de empleo derivadas del proyecto, que todavía fueron objeto de diversos trámites administrativos. El proyecto GPCISA sufrió modificaciones en el socio industrial y en los socios financieros inicialmente previstos, lo que obligó al gobierno a solicitar nuevas garantías. Veámoslo con más detalle.

En el marco del programa GARAPEN, el Gobierno vasco aprobó la concesión de ayudas por 2.000 millones de pesetas a las empresas estadounidenses Grotjhon Precise International y HR Industries, la mitad en efectivo y la otra mitad en terrenos ${ }^{30}$. Las ayudas iban encaminadas a crear una empresa conjunta con socios extranjeros para producir circuitos multicapa y abrirse un hueco de aproximada mene el $1 \%$ del mercado europeo. El gobierno se propuso analizar el proceso «in situ»

${ }^{29}$ Expediente 05\06\03\03\0010, V Leg., Comisión de Industria y Agricultura, Diario de Sesiones del Parlamento Vasco, 19 de octubre de 1995. Mientras anunciaba el cierre inmediato de la planta de Zierbena especializada en el negro de carbono, Cabot proyectaba duplicar su producción en Shanghai, China: ICIS Chemical Business, 16 de mayo de 2003; Castillo, 1987, pp. 129-155.

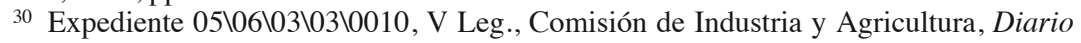
de Sesiones del Parlamento Vasco, 19 de octubre de 1995. Precise y HR Industries facturaban en Estados Unidos unos 2,5 y 1,3 millones de dólares respectivamente. Fue relegado a la categoría de «talleres» o «chiringuitos» empresariales por la oposición en el parlamento vasco. 
para comprobar los avances que se estaban realizando y contrastar las informaciones que de sus actuaciones en Estados Unidos daba la empresa. Para ello decidió que el director general de Sociedad Capital Desarrollo de Euskadi ${ }^{31}$, responsable del ámbito económico-financiero del proyecto, y una persona del departamento internacional de la SPRI, encargado del proyecto, se trasladasen a Estados Unidos con el fin de comprobar los avances. Los delegados observaron que uno de los grupos financieros del proyecto se había modificado y que una nueva empresa, en apariencia más fuerte, se había hecho cargo del proyecto en su totalidad. La delegación solicitó confirmación oficial de la nueva realidad y garantías reales, a lo que la empresa respondió con la promesa de presentarlas de inmediato. Durante la estancia, los representantes desplazados fueron informados de que, debido a problemas internos entre promotores, la empresa HR Industries había decidido abandonar el proyecto. Sin embargo, el órgano internacional de la SPRI había avanzado con la definición de una red de penetración y el establecimiento de preacuerdos de trabajo con una empresa internacional en el ámbito europeo. Por su parte, los promotores habían iniciado tareas previas a la construcción de la planta - planos de situación, proyecto de arquitectura - y sometido el plan de formación de personal al Gobierno vasco para su análisis y prospección de ayudas. Se trataba de un plan de formación que rebasaba con creces los 100 millones y con expectativas de formación técnica en Estados Unidos. Al cierre del acuerdo con el nuevo grupo financiero le siguió el compromiso para la aportación de todas las garantías entre los inversores y prestamistas, a la espera de cerrar las operaciones y poner en marcha definitivamente el proyecto en una visita de los promotores industriales y financieros al País Vasco. Por otro lado, los responsables del gobierno contactaron con varias empresas autóctonas para explicarles el proyecto como plan de inversión, construcción y fabricación a realizar en el País Vasco.

Halló un socio industrial y selló un protocolo de intenciones con el grupo industrial de la automoción y la electrónica Saturn Electronics \& Engineering, Inc., que en octubre de 1996 presentó un plan de empresa para una planta de circuitos integrados multicapa, ligeramente alejado del proyecto inicial. Según el mismo, Saturn adquiriría en su totalidad las acciones de GPCISA si el proyecto resultaba asumible. SPRI evaluó el pro-

31 Plaza, 2000, p. 4. 
yecto presentado y las diferencias respecto al inicial y, por su parte, el Grupo Saturn aceptó que se hiciera una auditoría previa a cualquier actuación. Personal especializado dependiente del gobierno realizó una visita a Saturn y emitió un informe positivo sobre la situación y capacidad del Grupo para llegar a buen puerto. Poco antes de finalizar 1996, el gobierno requirió a Saturn la ratificación oficial de su intención de continuar el proyecto previsto y la presentación de un plan detallado del mismo. Satisfechos los anteriores requisitos, el gobierno notificó al Grupo Saturn su disposición favorable de presentar su proyecto a la Oficina de inversiones estratégicas. Finalmente, el Grupo Saturn declinó seguir adelante con el proyecto por dificultades surgidas probablemente en la propia relación con los socios financieros en Estados Unidos, sin que el gobierno hubiese abonado cantidad alguna ${ }^{32}$.

\section{La conjunción de iniciativas: INDELEC}

Cuando nació la empresa sobre la que se centra este relato, las comunicaciones móviles contaban varios años de existencia en España. Valgan unas líneas sobre sus orígenes, sin ánimo alguno de exhaustividad.

En un escenario de un futuro altamente prometedor para el desarrollo de las comunicaciones móviles, la CTNE empezó a prestar el servicio de comunicaciones marítimas con los buques en alta mar en 1970, seguido de inmediato por los servicios a las concesionarias de autopistas de Cataluña y del norte de España. Asimismo, la operadora cerró diversos acuerdos para atender la demanda de radiotelefonía imposible de satisfacer con las redes establecidas para uso general ${ }^{33}$. La CTNE empezó a dotarse de equipos móviles capaces de resolver situaciones de emergencia o de asegurar el seguimiento de acontecimientos especiales en cualquier rincón de España y, en 1972, puso en marcha el servicio

32 Comparecencia del Consejero de Industria, Agricultura y Pesca, a petición propia, al objeto de informar acerca del «Proyecto Grotjhon Precise Connection International», Expediente 05\06103\03\0030, V Leg., Comisión de Industria y Agricultura, 27 de febrero de 1997.

${ }^{33}$ CTNE, Memoria 1971, p. 37; para una evolución del Servicio y sus características técnicas, véase Elias, Berenguer y Mataix, en Calvo, 2016, pp. 85-158. En las autopistas el servicio requería parejas de postes de auxilio, estaciones repetidores de radioenlaces y equipos de la red móvil: CTNE, Memoria 1982, p. 22. 
mensafónico o de radiobúsqueda, que, al cabo de un decenio alcanzó los 9.518 abonados $^{34}$.

Parece existir consenso en atribuir el origen del teléfono móvil en España al Teléfono Automático en Vehículos (TAV), llamado al principio 'teléfono automático en vehículo', que inició el periodo de prueba en 1974 en las áreas de Madrid y Barcelona con capacidad para 400 abonados en cada una de ellas. En diciembre de 1975 - y no en 1976, como por lo general se afirma-, comenzaron a prestar servicio las nuevas instalaciones en Madrid y, al año siguiente, se extendió la cobertura a Gerona mediante equipos con una capacidad de doce radiocanales en la estación de radio del Montseny (Barcelona). La TAV fue desplazada por el sistema móvil celular analógico de primera generación (1G), denominado la Telefonía Móvil Automática (TMA), que se hizo esperar varios años. Lo puso en marcha la Compañía Telefónica Nacional de España con ocasión del Campeonato Mundial de Fútbol, celebrado en España en 1982, operaba en la frecuencia de 450-470 megahercios, se basaba en el estándar NMT450 de la Nordic Mobile Telephone y usaba terminales, que, aun siendo muy pesados, podían ser transportables ${ }^{35}$. Las líneas TMA en servicio casi se quintuplicaron entre 1988 y 1993, a partir de las 11.600 de 1988. En 1990, este servicio TMA amplió su oferta con la implantación del sistema que operaba en la banda de 900 megahercios (TMA-900A) ${ }^{36}$.

${ }^{34}$ CTNE, Memoria(s) anual(es). Un locutorio móvil funcionó por vez primera en la vuelta ciclista a España, se ensayaron las primeras centrales en contenedores transportables y se incorporaron los primeros radioenlaces móviles sobre remolques: CTNE, $M e$ moria 1972, pp. 43-44. Bélgica y Holanda (1965) se adelantaron en el servicio de radiomensajería analógica con el Sémaphone, disponible después en Luxemburgo (1981). Francia puso a punto su estándar analógico Eurosignal en 1975 y lo propio hizo el Reino Unido tres años después con un código y formato para sistemas nacionales de radiomensajería - gran capacidad y amplia área - desarrollado por un grupo del Post Office denominado Post Office Code Standardization Advisory Group (POCSAG). Fue adoptado en 1981 como estándar internacional por el Consultative Commitee for International Radio (CCCRI) en competencia con los otros estándares de tercera generación - el de NEC y el Golay de Motorola: Soret (1991), p. 75; Boucher, 1992, p. 265-. Hacia 1994, Asia concentraba el mayor número de dispositivos y EE.UU. presentaba las tasas de penetración más altas en el servicio de radiomensajería: Bekkers, 2001, p. 417.

35 Elias, Berenguer y Mataix, en Calvo, 2016, pp. 85-158. Sin duda, se trata de los terminales móviles de uso individual, que la CTNE reservaba estrictamente a los altos cargos: Conversación del autor con Luis Solana Madariaga, Madrid, 8 de marzo de 2016.

36 CTNE, Memoria(s) 1974, p. 16; 1975, p. 19 y 1977, p. 12 y 1990, p. 11; Telefónica, Memoria 1990, p. 30. 
Durante la etapa en estudio la telefonía móvil atravesó por dos fases nuevas de cambio tecnológico con el desarrollo y despliegue de la segunda y la tercera generación, basadas en el estándar paneuropeo digital GSM y en el universal UMTS, respectivamente. A las novedades tecnológicas ambos unían una novedad en el sistema de explotación por la introducción de la competencia ${ }^{37}$.

Esta obligada referencia a los orígenes y evolución del teléfono móvil en España sirve de presentación de una de las empresas que tendrá un papel central en la creación de la protagonista de este relato a la vez que de marco general en el que se inscribe la trayectoria de esta. Bajo una fórmula idéntica a la aplicada en el caso de la microelectrónica y la fibra óptica con AT\&T y la japonesa Fujitsu, respectivamente, Telefónica creó una empresa conjunta con líderes tecnológicos en el campo de las transmisiones. Esta aceptación de empresas conjuntas con el capital público fue una conducta similar a la seguida por la multinacional alemana Siemens - la creación de Tefosa en Asturias - y diametralmente opuesta a la adoptada años antes por la propia Fujitsu al crear Fujitsu España, valgan por $\operatorname{casos}^{38}$. El proyecto, de menor fuste que los señalados, si bien repetía la fórmula de la asociación con multinacionales, tenía la singularidad de apoyarse en el sector público no estatal - no parece insignificante señalar aquí la incidencia del nuevo marco autonómico - y de buscar un efecto demostración. Veamos los antecedentes.

En 1982, el Gobierno vasco adjudicó por concurso la ampliación de la red de comunicaciones móviles para la policía a la filial de Telefónica Hispano Radio Marítima (HRM), en competencia con la división de electrónica e informática del INI. La resolución puso como condición que la fabricación de los equipos corriera a cargo de una empresa del territorio autónomo vasco, a saber, Radio Industria Bilbaína (RIB), filial de HRM y proveedora también de equipo para la policía autonómica. HRM se comprometió a un plan de industrialización, que exigía reestructurar la em-

37 Casi tres años mediaron entre el lanzamiento de la oferta comercial del servicio GSM en la Comunidad Europea a finales de 1992 y el inicio de la explotación comercial del servicio GSM por Telefónica, seguida al cabo de unos meses por la Alianza Internacional de Redes Telefónicas SA, primitivo nombre de Airtel Móvil: Diario Oficial de las Comunidades Europeas, 76, 18 de marzo de 1997, pp. 19-29. Ericsson España suministró el primer sistema de telefonía móvil GSM a Telefónica, de cuya red Ericsson era el principal proveedor. Tras la apertura del mercado a la competencia, Airtel (ahora Vodafone) en 1995 y Amena en 1998 se convirtieron en clientes de Ericsson.

38 Calvo, 2017, pp. 51-62. Para contextualizar, véanse Guillén, 2002 y Calvo, 2016. 
presa e inversiones en activos fijos. Sobre tal base el gobierno de Vitoria buscó colaborar con CTNE en un genuino proyecto industrial que se hiciese cargo de RIB, al amparo del prometedor mercado institucional de la comunidad autónoma vasca - unos 6.000 millones ptas. - y de los fuertes incentivos que ofrecía a las nuevas iniciativas industriales ${ }^{39}$.

Por su parte, CTNE había identificado en su largamente esperado plan cuatrienal la problemática de los teléfonos móviles en una situación de vacío en la ordenación industrial y de gran mercado potencial. Se daban todos los requisitos para embarcarse en una aventura común con las autoridades vascas, que prometía subvenciones públicas y mercado para los productos del grupo de Telefónica. La operadora monopolista de telecomunicaciones se mostraba abierta a la participación de una multinacional como socio tecnológico e instrumento de penetración en el mercado exterior dentro de un acuerdo general de colaboración o de acuerdos específicos para determinados productos, con responsabilidades de gestión en el primer caso $^{40}$.

Pasemos a los planes y a los participantes. La empresa por crear contaba con absorber RIB y tener desde un centro de I+D hasta una red comercial, de ingeniería y de asistencia técnica. En sus perspectivas, podría conseguir el 30-40\% del mercado español de móviles y exportar un 30\% de la producción. El capital inicial se cifraría en 300 millones ptas., aportado en su mitad por CTNE y en la restante por las vascas Sociedad de Promoción y Reconversión Industrial (SPRI) y Desarrollo de Nuevas Actividades (DENAC), filial de Aceriales ${ }^{41}$.

39 Calvo, 2016. Radio Industria Bilbaína fue fundada durante la Segunda República por capitalistas nacionales - Antonio Muñoz Villamil - y extranjeros - el holandés Lamberto Lucas y el belga Gustavo Fraikin - y empleaba técnicos foráneos: Calvo, 2014, p. 87. HRM se publicitaba como proveedora de TSH, telefonías, autoalarmas, radiogoniómetros, detectores de pesca y fondo, radar y megafonía. Tenía la dirección y oficinas en Madrid y 30 inspecciones en España: Ingeniería Naval, julio 1967, p. 7.

40 Telefónica en colaboración con la SPRI construyó un telepuerto como centro de todo el sistema de telecomunicaciones del País Vasco: Cambio 16, 999-1001, 1991, p. 16.140 .

${ }^{41}$ Libros de Actas del consejo de administración, Telefónica, 28/3/1984; Telefónica, Memoria 1984, p. 39. en 1983 Aceriales creó DENAC, especializada en infraestructura y logística y con el fin de ofrecer un servicio integral a las iniciativas empresariales y, a semejanza de British Steel, contrarrestar los despidos resultantes de cierres de acerías en la región vasca y en respuesta tanto a presiones sindicales como del gobierno autónomo: European Communities Commission (1989), pp. 195-198; El País, 17 de noviembre de 1983. Algunos indicios apuntan a la continuidad en el tiempo de esa orientación al mercado in- 
En un escenario de incorporación de un socio multinacional, la CTNE le cedería el $20 \%$ y los otros socios el $5 \%$, mientras que si la misma no tenía lugar, trasferiría el $20 \%$ a otras empresas privadas. Con ese primer tablado ya en pie, Telefónica veía importante romper la relación entre RBI y HRM mediante la compra de RIB. Finalmente, Telefónica atrajo a Philips y lideró la creación de Industria Electrónica de Comunicaciones (INDELEC) para fabricar radioteléfonos - los móviles de entonces - en el parque tecnológico de la localidad vizcaína de Zamudio, el buque insignia del ejecutivo autonómico ${ }^{42}$. La configuración definitiva de INDELEC se consumó con diversos pasos de carácter tecnológico, laboral, mercantil y financiero. Consistieron en la entrada de Philips como socio promotor y tecnológico, el acuerdo de integración del personal de Philips del área de radiocomunicaciones móviles en INDELEC y la cesión a la misma de este mercado y de su importante base de clientes. Los pasos se completaron con la elaboración de los planes estratégicos y de inversiones y petición de ayudas a los organismos oficiales y en especial a la ZUR del Nervión ${ }^{43}$.

El esquema seguido observó una pauta de integración de capital privado y público, modalidad que introducía matices a ciertos precedentes en el sector de la electrónica de consumo ${ }^{44}$. Telefónica, Philips Ibérica S. A.

ternacional, como muestra la participación en una delegación de empresas en el importante mercado de Francia, señalada en otro lugar: Gobierno Vasco, 2004, p. 428.

${ }^{42}$ Historiadores económicos han recogido así su creación: «[La SPRI] También impulsó la creación de la telefonía móvil poniendo en marcha en 1984 el proyecto IndelecEricsson»: López García y Valdaliso, 2008, p. 5. La bibliografía internacional sitúa la empresa en Bilbao sin remilgo alguno: Meurling y Jeans, 2000, p. 389. Curiosamente, el nombre coincidía con el del Indelec Holding AG, filial de Swiss Bank Corporation: Prior notification of a concentration, (Case No IV/ M.789 - Enderly/ SBE), (96/C 187/06), Official Journal of the European Communities, 27 de junio de 1996. El comité de empresa de HRM puntualizó que debido a cuestiones de viabilidad, Telefónica tenía la intención de reducir la plantilla a la mitad y se mostró abiertamente contrario a la nueva empresa, que si bien creaba 122 puestos de trabajo dejaba a 200 trabajadores ante un futuro incierto: El País, 14 de abril de 1984. En 1985 SPRI, la Diputación Foral de Bizkaia y el Ayuntamiento de Zamudio formaron la Sociedad Pública Parque Tecnológico-Teknologi Elkartegia y el parque, estratégicamente conectado con el aeropuerto, fue pionero en España: Iraila, septiembre de 2010, p. 28.

${ }^{43}$ La integración en INDELEC de la red de ventas, el servicio de asistencia técnica, instalaciones y el departamento de ingeniería de sistemas de Philips que desarrollaban su actividad en el campo de las radiocomunicaciones móviles tuvo lugar a comienzos de 1986: INDELEC, 1986, p. 5.

${ }^{44}$ La SPRI tenía una participación mayoritaria en el capital social fundacional del Parque Tecnológico de Zamudio, con un 51\%; el resto se repartía entre la Diputación Foral de 
E., DENAC y el Gobierno vasco a través de la SPRI participaban en INDELEC con el 30,26, 22, y 22\%, respectivamente. Si bien a esta actuación se le asignaba un carácter de ensayo, los impulsores preveían repetir el modelo en todo rincón del país precisado de ayuda, inversión o empuje. Por su parte, Philips ensayó aquí su futuro programa de alianza estratégica al servicio de una red de firmas pequeñas de alta tecnología ${ }^{45}$.

INDELEC afrontó su andadura con medidas de carácter financiero, laboral y organizativo. Mediado 1986, realizó una ampliación de capital desembolsado de 300 a 600 millones de pesetas para hacer frente a las inversiones en capital fijo y circulante y a las grandes expectativas de expansión. La plantilla de producción aumentó en un $132 \%$ con respecto al año anterior, se introdujeron sistemas automáticos de pruebas in-circuit para el grueso de subconjuntos, así como sistemas informáticos de pruebas. Los primeros permitieron detectar los posibles fallos en las fases más tempranas y estos últimos un aumento de la eficiencia y de la garantía en la calidad de los procesos productivos. INDELEC potenció el departamento de ingeniería de sistemas a través de equipos informáticos para el

Vizcaya (48\%) y el Ayuntamiento de Zamudio (1\%). Con posterioridad, la SPRI hubo de tomar un $50 \%$ más de participación que la inicial, de forma que la composición quedó así: SPRI, 74,9\%, Diputación Foral de Vizcaya, 24,53\% y Ayuntamiento de Zamudio, 0,57\%: Sobre el capital social del Parque Tecnológico de Zamudio, expediente 07/10.05.03.0232, 19 de diciembre de 2001; Ondategui (2001, p. 89) redondea los números: Gobierno vasco (SPRI) 74,8; Diputación Foral de Vizcaya 24,6; Ayuntamiento de Zamudio 0,6. Un plan de viabilidad para las tres principales industrias nacionales del sector de electrónica de consumo preveía una línea de crédito para la creación de una nueva empresa nacional del denominado sector marrón, que incluye aparatos de radio, televisión, equipos de alta fidelidad y electrónica de uso doméstico: El País, 10 de agosto de 1982. La industria de componentes electrónicos quedó incluida en la reconversión por Real Decreto 769/1982, de 26 de marzo: BOE, 95, 21 de abril de 1982, pp. 10.066-10.068.

45 Constitución de Control Electrónico Integrado (CEISA) con 44 millones ptas. Para Philips: European Communities Commission, 1989, p. 192; variantes de la participación en INDELEC-Telefónica, Philips y el Gobierno Vasco con el 30, 20 y 26\%, respectivamente: Castells, 1986, p. 148; curiosamente, Philips reforzó su peso en INDELEC antes de ser reemplazada por Ericsson como socio tecnológico: Computer Business Review, 26 de abril de 1989; El País, 16 de febrero de 1993. En 1995, Telefónica tenía una participación del 20,14\% en el capital social: Comisión Nacional de Mercado de Valores, Hechos relevantes, 4.915, 19 de abril de 1995. INDELEC alcanzó en 1986 un volumen de facturación de 1.205.664.879 y al año siguiente rebasó los 2.000 millones de pesetas, casi $66 \%$ más que en años anteriores: INDELEC, 1986, p. 5; AHCIET, 22, 1987, p. 133. En el ejercicio de 1986 tuvo lugar el definitivo saneamiento económico y financiero de Radio Industria Bilbaína y la absorción de su personal: INDELEC, 1986, p. 5. 
cálculo de redes y creó el departamento de proyectos como instrumento de coordinar, dirigir y gestionar aquellos proyectos complejos. Finalmente, la empresa tendió a incorporar personal más cualificado y promovió la formación del personal en cooperación con los fondos de promoción de empleo. En poco tiempo, el peso del personal titulado en el conjunto pasó de poco más de la cuarta parte a casi un tercio (Gráfico 3$)^{46}$.

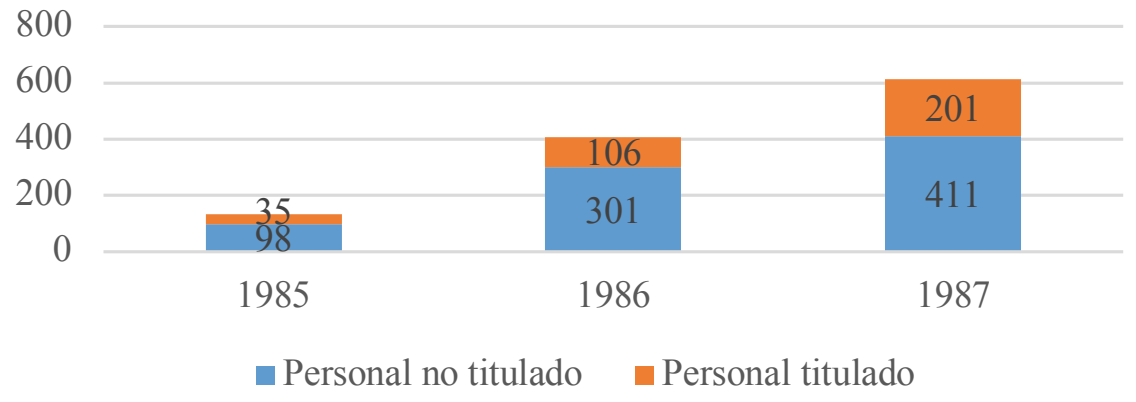

Gráfico 3

INDELEC: evolución de la plantilla según cualificación, 1985-1987

Fuente: elaboración propia a partir de INDELEC, 1986, p. 11.

Desde el principio, la demanda de Telefónica significó una base fundamental para la subsistencia misma de la empresa. La operadora pasó a INDELEC importantes pedidos de estaciones base de telefonía móvil automática, equipos no incluidos inicialmente en el contrato de transferencia de tecnología, incluso antes de que fueran fabricados por la empresa. Ese hecho amplió la presencia de la empresa en el campo de la telefonía móvil celular de crecimiento futuro muy importante. Por su parte, la penetración del mercado interior se asentó en una red comercial de pequeñas empresas distribuidoras, centrada en Madrid pero extendida a otras zonas. De momentos tempranos fueron las oficinas de Madrid y Barcelona y las delegaciones de Sevilla y Bilbao. Temprana fue asimismo la reorganización del

${ }^{46}$ INDELEC, 1986, pp. 8 y 11. Destaca la introducción de técnicas de flexibilización de la producción con efectos en la reducción de los stocks en curso y los de producto terminado: INDELEC, 1986, p. 5. 
servicio de asistencia técnica en instalaciones con un aumento del número de personas y la dotación de instrumental y equipos ${ }^{47}$.

Apenas cuatro años después de su fundación, cabalgando sobre una pujante demanda de las comunicaciones móviles y una presencia creciente en este mercado, INDELEC llevó a cabo una expansión de su capacidad productiva. La nueva fábrica en el Parque Tecnológico del País Vasco perseguía una mejor adecuación a los avances tecnológicos que reunía su Teléfono Móvil Automático o la calidad de resolución de sus radiobúsquedas en la radiomensajería, sin olvidar la eventualidad de colaborar con otras empresas tecnológicamente avanzadas, enclavadas en lugares próximos, o con pymes de nicho, aspecto este casi desconocido ${ }^{48}$.

La expansión se aquilató con la innovación, ya que INDELEC incorporó a su proceso de fabricación nuevas unidades CAD-CAE para el diseño por ordenador de sus productos y cuadruplicó las unidades de inserción automática de componentes. En el campo de la Investigación y Desarrollo, INDELEC desarrolló una doble línea de actuación. Por la primera, creó un departamento propio de I+D, desde el que impulsó importantes proyectos, algunos de ellos con destacadas empresas internacionales ${ }^{49}$. Por la segunda, aprovechó las ventajas del clúster forjando acuerdos de colaboración con centros técnicos del país en busca de talento y nuevas ideas. En la etapa de Philips, con un modesto departamento de I+D reducido a unas quince personas, INDELEC dependía de la tecnología del centro de Cambridge (Reino Unido). Los desarrollos que se hacían eran más bien adaptaciones

47 INDELEC, 1986, p. 5. En Madrid figuraban siete empresas (Audio Centro, Autophone, Auto Radio FM, Maiden, Radio Automóvil, Siteleg Radio y Teleco Ibérica); en Alicante una (Telecomunicación de Levante; en Sevilla una (Visa Sur Telecomunicaciones): ABC, 29 de octubre de 1990; Valle de Elda, 27 de octubre de 1989. El equipo comercial alcanzó a finales de 1986 un total de 27 empleados: INDELEC, 1986, p. 8.

48 Deducimos la afirmación de testimonios de protagonistas, como el referido a un contrato de distribución, servicio de instalación y mantenimiento con J.J.N.Electronica, una empresa con cuatro empleados en plantilla.

$49 A B C, 27$ de febrero de 1987. Entre los primeros proyectos de I+D destacan tres, uno de ellos en solitario (desarrollo de un interfaz FFSK con el ordenador de abordo para sistemas de control de tráfico de autobuses urbanos). Dos proyectos fueron llevados a cabo en colaboración dentro de un proyecto internacional (desarrollo de un sistema CAD para el desarrollo de software y de un chip en tecnología CMOS que permitía supervisar el software - watchdog-, informar sobre Origen de Reset y una reducción del consumo de la unidad de control a la mitad, función de suma importancia en los diseños de los futuros radioteléfonos): INDELEC, 1986, p. 7. INDELEC se convirtió distribuidor oficial del servicio de buscapersonas en el nuevo proyecto Mensatel de Telefónica: ABC,20 de octubre de 1989. 
de los productos a las necesidades de los clientes. Con Ericsson, INDELEC pasó a depender de Kista en I+D, un ecosistema de innovación en las cercanías de Estocolmo que despegó en la década de 1970, y de Kumla y Lund en productos ${ }^{50}$. En esta etapa, INDELEC llegó a ser uno de los principales centros tecnológicos del Grupo fuera de Suecia. El centro de I+D en España tenía diversas competencias a escala mundial ya que concentraba no pocos recursos financieros, técnicos y humanos - 7\% de la facturación, 41,6\% de una plantilla total de 1.200 personas -; otras 500 empleos correspondían a un centro de servicios postventa para toda África, Oriente Medio y gran parte de Europa, y los 200 restantes a un tercer centro contable-administrativo, encargado de la contabilidad legal en unos 60 países. No resulta extraño que cooperase con las más prestigiosas empresas de comunicación del continente en el ya citado proyecto ERMES de radiomensajería, así como en otros siete proyectos continentales. Aportaciones importantes fueron el desarrollo de un Interface FFSK con el ordenador de abordo para sistemas de tráfico de autobuses urbanos o el desarrollo de un secráfono para su incorporación en radioteléfonos móviles y portátiles $^{51}$.

INDELEC desarrolló un teléfono propio e impuso al mercado sus propias especificaciones, de manera que vendía lo que la empresa fabricaba, a diferencia de lo que sucedía en la etapa de Telefónica.

La entrada de Ericsson supuso un cambio sustancial en los métodos de fabricación. Con Philips el montaje era manual, mientras que con Ericsson se introdujo la robotizacion en el montaje superficial, que permitió aumentar enormemente el volumen de producción y la productividad ${ }^{52}$.

Por más interpuesta que fuese, la participación del Gobierno vasco en INDELEC, parecía garantizar una demanda cautiva. Sin embargo, no siempre fue así para gran sorpresa de algunos y, obviamente, para perjuicio de la empresa. El suministro e instalación de una red de radio móvil digital fueron adjudicados por un importe de 2.105 millones de pesetas en concurso público y a tres días de finalizar el año 1.990 a Siemens, pro-

50 Entrevista del autor a José Miguel de Diego Rodrigo, 11 de marzo de 2019. Inicialmente, se preveía que el departamento tuviera un total de 16 empleados a plena dedicación; pronto se fortaleció la experiencia del personal titulado con estancias de formación en fábricas y centros de diversos países extranjeros: INDELEC, 1986, p. 5.

51 ABC, 26 de octubre de 1989; Fernández de Santos, 2010. Desde 1986, ingenieros de INDELEC participaban en el desarrollo de un nuevo terminal móvil, proyecto que se llevada a cabo en Holanda. INDELEC recibió subvención pública del CDTI para el desarrollo de terminales del proyecto ERMES: CDTI, 1990, p. 76.

52 Entrevista del autor a José Miguel de Diego Rodrigo, 7 de marzo de 2019. 
veedor que ofreció el sistema más adecuado a juicio del cliente. Bautizado como Proyecto Ainhoa, se dividía en dos fases bien diferenciadas, si bien complementarias. Consistían en la implantación de un sistema trunking isofrecuencial con acceso múltiple en la primera y de un sistema digital para subsanar las carencias de la red analógica en la segunda. Por tanto, el Proyecto Ainhoa tenía las características de un sistema de telefonía móvil privada, a diferencia del Teléfono Automático de Vehículos (TAV), el Nordic Mobile Telephone (NMT) o el Total Access Communications System (TACS) de Telefónica, todos ellos sistemas «celulares» de telefonía móvil pública ${ }^{53}$. La adjudicación del proyecto se ajustó a ocho criterios primordiales, empezando por la posibilidad de una implantación gradual del equipo, sin interrupción de los servicios vigentes, y continuando por la óptima cobertura territorial y capacidad de ampliación sin frecuencias adicionales. El sistema competía con ventajas en volumen de tráfico para las frecuencias disponibles y prestaba su capacidad íntegra de comunicación en todo el territorio, sin necesidad de adaptaciones en la adjudicación de frecuencias. Tampoco tenía rival en mecanismos de seguridad contra sabotajes, rapidez de acceso al operador, sencillez de manejo por el agente del orden y plazos de entrega. Diversas prestaciones incorporadas al sistema facilitaban la gestión de las comunicaciones.

El Proyecto Ainhoa era uno de los servicios que se apoyaban en la red oficial de comunicaciones del departamento de Interior del Gobierno vasco. El coste presupuestado, ya señalado, se convirtió en un coste de 1.574.480.433 más 191 millones por ampliación de canales. El pago se efectuó en cinco ejercicios entre 1990 y 1994. En 1995, estaban pendientes de aprobación y pago 572.606.905 (fase II). La instalación de la Fase I de la red se inició en 1991 y después se extendió a los tres territorios históricos de la Comunidad autónoma. Al ser un sistema isofrecuencial, únicamente requería un canal de radio (es decir, un par de frecuencias) para el establecimiento de una comunicación, incluso si los miembros del grupo se hallaban en el área de cobertura de repetidores diferentes. El número de canales instalado bastaba para satisfacer el tráfico de llamadas generado por todos los grupos a los que daba servicio. Aun así, el sistema preveía las comunicaciones en una banda diferente, que exigía una concesión distinta. A su vez, la Red incorporaba mecanismos de salvaguarda sin

53 Contestación a la pregunta para su respuesta por escrito, formulada por D. Javier Madrazo Lavín (grupo Izquierda Unida/Ezker Batua/Berdeak, al gobierno en relación a

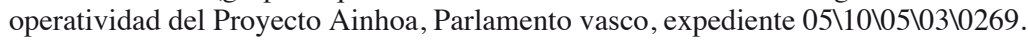


garantizar por ello la total inviolabilidad de la comunicación. El tiempo de establecimiento de llamadas resultó ser inferior al segundo y estaba garantizada la comunicación bajo las condiciones más desfavorables. Frente a las dificultades surgidas en el funcionamiento y operatividad del Proyecto Ainhoa y las quejas planteadas por los usuarios, el departamento de Interior trató de optimizar el funcionamiento de la red adaptando el software conveniente, a la vez que estudió las tecnologías y sistemas de secrafonía existentes en el mercado para mejorar la protección de la red. Frente a los recelos expresados, el Gobierno vasco señalaba que el sistema, lejos de estar en fase experimental, venía siendo utilizado por la Compañía Eléctrica ENEL en toda Italia y que le constaba que hubiese sido rechazado por ningún cuerpo policial. El mantenimiento del sistema Ainhoa estaba encomendado a TECOSA, mientras que hasta cuatro empresas se encargaban de prestar ese servicio de los restantes sistemas de comunicaciones. Al estar contemplada la optimización del Proyecto en la Fase II, su implantación no suponía coste adicional alguno, si bien la posibilidad de un replanteo técnico, en el caso de que la Dirección General de Telecomunicaciones no concediese las frecuencias necesarias, podría incrementar el coste final ${ }^{54}$.

\section{Reajustes, cambios de estrategia y relevo de los líderes tecnológicos}

INDELEC se había apoyado en la obtención de homologaciones y certificados de aceptación de sus equipos, un arma en manos de las nacionesestado a través de sus organismos especializados (la Dirección General de Política Tecnológica, en la ocasión) para erigir barreras no arancelarias a la entrada de equipos de telecomunicación. Se trataba de trámites administrativos necesarios para verificar que un producto o servicio funciona de acuerdo con las especificaciones incluidas en una norma o estándar técnico.

${ }^{54}$ Pagos por ejercicio: 285 millones de pts. en 1990 (fase I); 1991: 249.481.149 pts. (fases I y II); 1992: 499.544.723 pts. (fases I y II); 1993: 423.091 .619 pts. (fase II); 1994: 117.362.942 pts. (fase II); detalle de las empresas encargadas del mantenimiento de los restantes sistemas de comunicaciones: ALCATEL (transporte); ALTEL (buscapersonas y repetidores convencionales); SIEMENS (telefonía) y KEYTRON (comunicaciones RACAL): Contestación a la pregunta para su respuesta por escrito, formulada por D. Javier Madrazo Lavín (grupo Izquierda Unida/Ezker Batua/Berdeak, al gobierno en relación a operatividad del Proyecto Ainhoa, Parlamento vasco, expediente 05\10\05\03\0269. 
La telefonía móvil celular en España: políticas de gobierno y de empresas

\section{Cuadro 1}

Homologación de equipos de Indelec

\begin{tabular}{l|llll}
\hline Año & \multicolumn{1}{|c}{ Equipo } & Marca & \multicolumn{1}{c}{ Características } & \multicolumn{1}{c}{ Fabricación } \\
\hline 1989 & equipo emisor receptor móvil & Indelec & modelo FM 1000 & Zamudio (Vizcaya) \\
\hline 1990 & radioteléfono portátil Indelec & Philips & modelo PR-710 & Zamudio \\
\hline 1990 & emisor-receptor móvil VHF/UHF & Indelec & modelo PRM-80 & Zamudio \\
\hline 1990 & $\begin{array}{l}\text { repetidor-estación base sintetizado } \\
\text { VHF-UHF }\end{array}$ & (Indelec) & & Zamudio \\
\hline \multirow{2}{*}{1990} & emisor-receptor portátil (TMA- & Indelec & modelo I-6222 & Zamudio \\
\cline { 2 - 5 } & radioteléfono móvil UHF & Indelec & modelo PRM80-TMS & Zamudio \\
\hline 1991 & estación base VHF & Indelec & modelo FR-5000-A & Zamudio \\
\hline 1991 & equipo repetidor & Indelec & modelo I-6222 & Zamudio \\
\hline 1992 & estación base/repetidor VHF & (Indelec) & modelo FX-902 & Zamudio \\
\hline 1994 & radioteléfono portátil UHF & Indelec & modelo IP-149 & Zamudio \\
\hline
\end{tabular}

Fuente: elaboración a partir del Boletín Oficial del Estado.

El catálogo de INDELEC se componía de equipos emisores receptores móviles y portátiles; radioteléfonos portátiles y móviles, repetidores-estación base sintetizados VHF-UHF, estaciones base/repetidor, estaciones base VHF y equipo repetidores (Cuadro 1). Su oferta de equipos reconocidos por la autoridad competente superaba con creces en variedad la de otros competidores, entre ellos la británica Technofone LTD, con su planta de Camberley ${ }^{55}$. A partir de 1989, volvió a aparecer en el mercado la competencia asiática con el restablecimiento de la percepción de los de-

55 INDELEC publicitaba así varios tipos de equipos: el I7-1050 el portátil que une tecnología avanzada y diseño la comunicación en un bolsillo; I-4000 el teléfono para coche sólido fiable y de mayor autonomía el convertible más vendido en España y el I-6222 el portátil más potente del mercado adaptable también a su coche: $A B C, 23 / 7 / 1991$. Tecnophone fabricaba emisores-receptores portátiles (TMA-900-A) con marca propia y de Olivetti: BOE, 25 de abril de 1991. No parece adecuado calificar a INDELEC como empresa de considerable entidad y tamaño: Moreno, 2005, p. 531. 
rechos de aduana aplicables a varios tipos de receptores de telefonía, radiotelegrafía y radiodifusión originarios de China, beneficiaria de las preferencias arancelarias previstas por el Reglamento (CEE) $n^{\circ} 4257 / 88$ del Consejo de Europa ${ }^{56}$.

Consideraciones tecnológicas y de mercado se unieron para alterar la estructura de la propiedad de la empresa de radio móvil de forma gradual a lo largo de la década de 1990. Philips desinvirtió totalmente en INDELEC al ceder el 30\% del capital a la multinacional sueca Ericsson y el 10\% restante a la Sociedad de Promoción y Reconversión Industrial (SPRI). Perdió así la condición de socio tecnológico en favor de Ericsson, que atravesaba buenos momentos en Europa, mientras que la SPRI se hizo con el $40 \%$ del capital y destronó a Telefónica como principal accionista ${ }^{57}$. La estructura del capital se mantuvo en la ampliación del capital social en 625 millones de pesetas a mediados de la década, suma destinada al plan de inversiones en activos industriales para producir terminales móviles en Zamudio ${ }^{58}$.

INDELEC se vio abocada a la reestructuración para concentrar su actividad en el desarrollo y fabricación de equipos celulares, cimentada en la transferencia tecnológica de Ericsson. En ese proceso se desprendió del departamento de distribución de terminales celulares, vendido a Lanmóvil, nueva unidad de negocio de Landata, del Grupo IBV, y abrió una planta de líneas de montaje con una inversión inicial de 700 millones de pesetas en Zamudio ${ }^{59}$. Estas acciones pasaron factura a INDELEC, que engrosó la

56 Diario Oficial de las Comunidades Europeas, 86/29, 30 de marzo de 1989. Altos dirigentes del sector reconocían las dificultades («bache») de la empresa: Diario de Sesiones del Congreso, 20 de mayo de 1992, 18-Comisiones, p. 18.

57 El País, 16 de febrero de 1993; expansión de Ericsson en Europa: Ericsson, 1995, p. 6.

58 La SPRI concedió a INDELEC un crédito de 250 millones de ptas. el 14 de Junio de 1994 y actuó de mediadora cuando el gobierno vasco tomó una participación del 40\% en la ampliación de capital de INDELEC. Esta aportación quedaba condicionada a que INDELEC amortizase en su totalidad el recién mencionado crédito de 1994. Por su parte, la SPRI recibió autorización para renunciar a su derecho preferente de adquisición de la totalidad de las acciones de INDELEC propiedad de Telefónica. La autorización se extendía a conceder una opción temporal - por un periodo de dieciocho meses - de compra sobre la totalidad de sus acciones en INDELEC a Ericsson: Boletín Oficial del País Vasco, 213, 9 de noviembre de 1994.

59 Landata fue creada en 1985 por profesionales de la informática con el objetivo puesto en la compatibilización de los sistemas informáticos, un problema pendiente por resolver en las empresas. Tras los desastrosos ejercicios de finales de la década y comienzos 
lista de empresas deficitarias, por mucho que el volumen de negocio hubiera crecido de forma clara ${ }^{60}$. Telefónica, forzada por la Unión europea a desprenderse de su participación por su condición de operadora, vendió a Ericsson el 20,7\% que aún conservaba en INDELEC ${ }^{61}$. En junio de 1996, la multinacional sueca se convirtió en la dueña absoluta de la empresa al adquirir el $10 \%$ en manos de BBK. Era el fruto de la perseguida respuesta al reto de diversificar la producción de equipos de conmutación, afincada en la fábrica de Leganés, y dotarse de capacidad industrial en el segmento de la radio para convertirse en un proveedor completo de telefonía móvil y competir con Motorola ${ }^{62}$.

de la de 1990, ocasionados por el avance de la informática, tuvo lugar la entrada de Proindesa, rama industrial de Iberduero, en el capital (40\%). El nuevo socio apostó por la ingeniería de telecomunicaciones en el negocio de redes privadas, sucesivamente de datos y de voz. En 1992, la Corporación IBV, integrada por BBV e Iberdrola, sustituyó a Proindesa como socia de Landata según una tendencia de participación accionarial hasta alcanzar el $74,25 \%$ en un primer peldaño y el $93,92 \%$ en 1998 . A su habilidad de situarse en nichos de negocio con gran valor añadido - servicios de ingeniería de telecomunicaciones, telefonía móvil y televisión por cable - se sumó su capacidad de aprovechar el viento favorable de la liberalización de las telecomunicaciones y el boom de la telefonía móvil. Entre 19931998 multiplicó su facturación por 18, pasando de 731 millones de pesetas, y su plantilla se quintuplicó. Al despegue de ventas contribuyó poderosamente la eclosión de redes digitales y, más específicamente, un acuerdo con Ericsson en 1995 por el que Landata compró en exclusiva los derechos de comercialización y distribución de los teléfonos móviles de INDELEC, que pasó de vender 11.000 móviles anuales a medio millón en 1998: El País, 14 de septiembre de 1998.

60 Telecompaper, 29 de marzo y 2 de noviembre de 1995. La cifra de negocios de la compañía alcanzó en el ejercicio de 1994 los 3.052 millones de pesetas, con un incremento de casi un 40\%; el capital, cifrado en 2.025 millones de pesetas, se repartía entre los SPRI (40\%), Ericsson (29,3\%), Telefónica (20,7\%) y BBK (10\%): PCWorld, 1 de marzo de 1995.

61 Telefónica, Memoria 1995, p. 3. Ericsson abonó 420 millones de ptas. por las acciones al valor nominal: Comisión Nacional de Mercado de Valores, Hechos relevantes, 4.915, 19 de abril de 1995. A finales de la década de 1980, la filial de Ericsson en España había llevado a cabo una reestructuración - por otra parte similar a la de Alcatel-Standard Eléctrica - con miras a fortalecer y flexibilizar la estructura y la actividad de todo el grupo mediante la creación de un holding - Ericsson S. A.- y la segregación de las actividades de distintos mercados para adaptarse al final del monopolio de Telefónica. El holding Ericsson S. A. quedó integrado por cuatro empresas: la histórica Intelsa, Sistemas Avanzados de Telecomunicaciones y Redes de Ingeniería y Construcción (Redinco), especializada en infraestructuras. Redinco pasaba a controlar dos unidades: Fibroco, empresa productora de cables de fibra óptica en su planta de Santa Perpetua de Mogoda (Barcelona), e Ingeniería de Telecomunicaciones e Instalaciones (ITISA), dedicada a la instalación de redes y participada por la suiza Cables Carailloz (48\%): El País, 25 de octubre de 1989.

62 VV.AA., 2015, pp. 139-140. 
La nueva Ericsson España desplegó sus líneas de actuación en tres direcciones complementarias, consistentes en explicar las ventajas de la telefonía móvil, acelerar la llegada a España de la telefonía móvil de segunda generación según el estándar GSM (Global System for Mobile Communications) y posicionarse como líder del estándar. Parte de los esfuerzos tropezaban con una dificultad adicional porque Telefónica estaba invirtiendo sumas importantes en el despliegue de una red TACS (Total Access Coverage System) y, naturalmente, pugnaba por amortizar en lo posible la inversión antes de la llegada del GSM ${ }^{63}$.

Ericsson apostó por INDELEC en su estrategia de concentración de la fabricación de telefonía móvil del grupo en una única factoría de terminales móviles analógicos en todo el mundo bajo el estándar TACS, el de mayor demanda en Europa. Los planes de invertir en I+D 3.400 millones de pesetas durante el cuatrienio 1995-1998 en la planta vizcaína hacían del País Vasco el cuarto centro de producción de terminales analógicos de Ericsson, tras los de Suecia, Estados Unidos y Reino Unido. En dicha fábrica depositaba Ericsson la esperanza de reforzar su penetración en Europa y Latinoamérica $-90 \%$ de la producción destinado a exportar-, de alojar el centro de competencia mundial para I+D y de fabricación de terminales fijos y celulares ${ }^{64}$.

63 VV.AA., 2015, pp. 139-140. TACS era un estándar derivado del AMPS, desarrollado por Bell Laboratories y el centro de investigación ATT de Estados Unidos. INDELEC llegó a estructurarse en tres divisiones para especializarse en productos muy diferentes en su aplicación: FCT (Fixed Cellular Terminal), orientada a los mercados de los países subdesarrollados y la predilecta de Ericsson, módulos de datos y móviles robustos, producto muy adecuado para determinados servicios y que contó entre su clientela a los bomberos de Nueva York: Entrevista personal del autor a José Miguel de Diego Rodrigo, 7 de marzo de 2019.

${ }^{64}$ Ministerio de Industria y Energía, 1996, p. 120. En el año financiero de 1995, Ericsson España aumentó las ventas y las exportaciones un $40 \%$ (hasta \$ 735 millones y $\$ 33,6$ millones, respectivamente). Ericsson esperaba que el crecimiento continuara en 1996, con una ligera corrección a la baja. La planta de Zamudio producía componentes para las estaciones que se fabricaban en Suecia, Australia y Reino Unido. En 1996, planes iniciales para que INDELEC produjera teléfonos móviles GSM y estaciones base requeridas por Telefónica y Airtel no se cumplieron: Computer Business Review, 3 de octubre de 1996. La fábrica estaba pensada como único centro de producción de teléfonos NMT y analógicos bajo el estándar TACS - ambos sistemas «celulares» de telefonía móvil pública-, centro de fabricación de módulos SMD para teléfonos digitales a la vez que responsable único en I+D . INDELEC tenía en esos momentos capacidad para producir del orden de las 700.000 unidades: ComputerWorld, 20 de septiembre de 1996. También se habló de un plan industrial un tanto más amplio (periodo 1995-2000) con cifras de inver- 
De creer a la máxima autoridad de la multinacional, la comunidad autónoma vasca ofrecía un «entorno muy positivo para la actividad industrial» y «un nivel de formación muy alto en los trabajadores». Nada más distante de la valoración de General Electric sobre la candidatura de Asturias, cuando la multinacional norteamericana prefirió una zona sin una robusta cultura industrial, es decir, Murcia, a otra que sí la tenía, a saber, Asturias. Si traducimos para entender mejor, el entorno favorable quería decir un decidido apoyo del Gobierno vasco, en plena coincidencia con la visión que Ericsson tenía de las inversiones a largo plazo ${ }^{65}$.

La segunda mitad del año 1996 y el arranque del siguiente se caracterizan por procesos de reestructuración y especialización. En esos momentos, Ericsson vislumbraba ocho motores que podrían afectar a la industria de la información y que incluían aspectos generales de la economía, la regulación y el cambio tecnológico. Se trataba de la globalización y la internacionalización, la continua desregulación de las telecomunicaciones, la microelectrónica cada vez más capaz, la expansión del paradigma informático, Internet, la orientación al consumidor, la movilidad, las fronteras cada vez más borrosas entre las telecomunicaciones, los medios de comunicación y los datos ${ }^{66}$.

La multinacional reanudó la reestructuración y concentración de actividades con una reorganización de la sección de radio en España. Ericsson absorbió la sociedad Sistemas Avanzados de Telecomunicaciones S.A. (SATESA), heredera desde una anterior reestructuración de activos segregados de INTELSA, orientados a los mercados de telecomunicaciones privadas, y que se destinaron a comercializar equipos sofisticados para el ministerio de Defensa y otros clientes institucionales. La operación tenía como finalidad integrarla en Ericsson Radio a través de una filial, concentrar en una sola cabecera su sección radiocelular en España y convertir el centro tecnológico de Zamudio en una división autónoma de Ericsson Radio, como así sucedió en efecto ${ }^{67}$. En 1996 Ericsson Radio

sión de 6.000 millones de pesetas y la creación de 450 nuevos puestos de trabajo: El País, 23 de abril de 1996.

${ }^{65}$ El País, 14 de septiembre de 1996. Como es sabido, General Electric valoró positivamente la cultura industrial de Asturias pero se inclinó por las regiones más agrícolas con una cultura industrial en ciernes: Junta del Principado de Asturias, II Legislatura, Comisión de Industria, Energía y Comercio, Diario de Sesiones, 048, 25 de octubre de 1988.

66 Ericsson, 1996, p. 12.

${ }^{67}$ ComputerWorld, 20 de septiembre de 1996; Fernández de Santos, 2010; El País, 25 de octubre de 1989. 
Ángel Calvo

S.A. creó Ericsson INDELEC S. A. con un capital de 2.000 millones de pesetas, desembolsado en su totalidad ${ }^{68}$.

A principios de 1997, Ericsson reorganizó el conjunto del grupo especializándose en segmentos en los que la tecnología era el factor más competitivo en detrimento de los de bajo contenido tecnológico, cuyas actividades fueron transferidas a socios en esquemas globales. A continuación, la filial española completó la renovación de su modelo industrial mediante la instalación de las empresas SCI y Chatham, que se orientaron al ensamblaje de componentes en placas y a la fabricación de cables metálicos y de gabinetes ${ }^{69}$. La mano de obra se mantuvo estable en un promedio de 3.300 empleados, no sin experimentar un cambio sustancial en su composición según cualificación y edad ${ }^{70}$.

En 1998, Ericsson presentó un proyecto para el desarrollo de su nuevo centro en Zamudio por importe de 5.580 millones de ptas. de inversiones y 170 nuevos empleos al que el Gobierno vasco asignó 787,7 millones de ptas., cantidad no abonada por incumplimientos de la empresa en ambas vertientes de inversión y empleo ${ }^{71}$.

Asomaban, pues, dificultades pero las cuantiosas inversiones realizadas o anunciadas no presagiaban el final ni resguardaban contra el vendaval que acompañó al estallido de la burbuja de las punto.com. Una larga

${ }^{68}$ El Consejo de administración quedó formado por Jesús Javier Aguirre Bilbao como presidente, por Alfonso Castresana Alonso de Prado como secretario y por los consejeros Naeve Ingemar, Rafael Lindgren Raimo, todos ellos integrantes del organismo entre 1/07/1996 y 1/1/2001: Información Mercantil interactiva de los Registros Mercantiles de España, Registro Mercantil de Bizkaia, hoja bi-2.589, tomo 212, folio 34.

${ }^{69}$ Los planes de externalización de Ericsson, dentro de la reorganización global de su actividad fueron observados muy de cerca por la Comunidad de Madrid, debido a la implantación en ella de la multinacional: Diario de sesiones de la Asamblea de Madrid, III Leg. 68, 14 de noviembre de 1991, p. 1.206.

${ }^{70}$ En 1990, aproximadamente el $70 \%$ de la fuerza de trabajo estaba compuesta por obreros, pero a fines de la década estos solo representaban el 10\% de la fuerza de trabajo. La plantilla de Ericsson España aumentó constantemente durante la década, especialmente por la contratación de técnicos e ingenieros para la sección de telefonía móvil, al mismo tiempo que se rejuvenecía a través del cierre de la planta de Leganés (Madrid) en 1998 y de 700 despidos, de forma que el 52\% de la fuerza laboral tenía entre 26 y 35 años. La plantilla de Ericsson España se quedó en 3.700 trabajadores, el 37,8\% de los cuales se dedicaban al desarrollo de tecnología; la reducción de personal de la empresa coincidía con planes de ajuste en Siemens: Sánchez Reinón, 2002, p. 1.

${ }^{71}$ Respuesta escrita del Consejero de Industria, Comercio y Turismo a la pregunta formulada por D. ${ }^{a}$ María Teresa Rodríguez Barahona (Grupo Socialistas Vascos-Euskal Sozialistak), Boletín Oficial del Parlamento Vasco, 65, 18.10.2002, p. 6.494. 
serie de acontecimientos vitales se dieron cita en el año 2001. El más general suponía la crisis general del fabricante sueco, cuyas pérdidas de 69.859 millones de pesetas al cierre del tercer trimestre llevaron a anunciar la eliminación de 17.300 trabajadores (el 16\% de su plantilla mundial) para recuperar la rentabilidad perdida y detener la caída de los beneficios.

La deslocalización tocaba a rebato bajo la pauta fabless o empresas sin fábricas. A comienzos de 2001, el gigante sueco hizo pública la decisión de traspasar por completo sus fábricas y operaciones de fabricación a Flextronics en un acuerdo valorado en $\$ 5$ mil millones al año ${ }^{72}$.

En 1999-2003, Ericsson sufrió fuertes pérdidas operativas y una reestructuración radical, que abarcó deslocalización, tercerización y reducción de personal. Al compás de la desaceleración inesperada que siguió a unos años de crecimiento explosivo de las ventas de teléfonos móviles, Ericsson se inclinó por reducir su actividad industrial en España, con el consiguiente recorte de empleo en su planta de Zamudio. La multinacional sueca comunicó al gobierno vasco y a la opinión pública su intención de buscar un comprador para la planta de Zamudio. Ante el interés del grupo Mondragón Corporación Cooperativa (MCC) por estudiar la viabilidad de un proyecto cooperativo en el que podía encajar parcialmente o en su totalidad la planta de Ericsson, las dos partes sellaron un preacuerdo por el que la multinacional se comprometía a mantener el empleo hasta encontrar un nuevo socio ${ }^{73}$.

Hacia finales del año 2001, INDELEC firmó un acuerdo preliminar con MCC para integrar la planta de Zamudio dentro del grupo Mondragón, bajo el nombre de Centro Tecnológico de Bilbao. Sin embargo, debido a la presunta falta de un plan industrial y tecnológico claro, los sindicatos y el comité de empresa rechazaron la propuesta. En respuesta, Ericsson elevó el recorte de empleos a 850, el grueso de los cuales mediante reubicación en otras compañías y el resto a través de prejubilaciones, despidos voluntarios, reubicaciones y despidos forzosos. Las áreas más afectadas eran la radio, las operaciones y el soporte informático.

${ }^{72}$ Los ingresos de Ericsson rondaban los 12 mil millones \$ en 2000 y se estimaban en 20 mil millones al año siguiente; Flextronics tenía 150 fábricas y más de 70.000 empleados en 27 países: New York Times, 15 de febrero de 2001.

73 IGI, 2010, p. 648. La rentabilidad se redujo un $89 \%$ en el primer trimestre 2001 y los beneficios pasaron de 109.000 millones a 11.000: El País, 27 de junio de 2001; Parlamento vasco, Recepción de la respuesta por escrito enviada por el Gobierno, 26 de septiembre de 2001 . 
En ese mismo año, Ericsson llegó a un acuerdo para subcontratar la fabricación de terminales móviles a un grupo estadounidense con sede en Singapur y más tarde se asoció con Sony para fusionar la fabricación de teléfonos móviles de ambas en una empresa de nueva creación, Sony Ericsson Mobile Communications, años después rebautizada como Sony Mobile Communications, en una operación que entrañaba un nuevo reto precisamente para Nokia ${ }^{74}$.

INDELEC se desgajó en tres unidades de características distintas a partir de las actividades de la multinacional sueca. Una treintena de ex empleados de la planta de Ericsson en Zamudio, con Javier Larrucea y Carmelo Laz junto a otros tres promotores al frente -Fernando Agirre, Javier Jáñez y Gorka Agirre - crearon Owasys, que fabricaba terminales móviles adaptados y sistemas de comunicaciones inalámbricas entre máquinas. La iniciativa tuvo una buena acogida pero carecía de producto y no producía dinero. El considerable retraso en concebir una solución y disponer del producto provocó una respuesta insatisfactoria del mercado Owasys se vio abocada a la suspensión de pagos en 2005 y solo pudo resurgir con un adelgazamiento y la entrada de nuevos socios ${ }^{75}$. Las restantes empresas formadas como spin-offs de INDELEC-Ericsson fueron P4Q (1999), especializada en ingeniería y fabricación de sistemas electrónicos, en Alonsotegi, y Trelec BTC en Sondika. Ambas colaboraron con Owasys y esta adquirió una participación en $\mathrm{P}^{4} \mathrm{Q}^{76}$.

\section{Conclusiones}

Este artículo aborda desde un estudio de caso - el de la empresa de radioteléfonos INDELEC - la imbricación del capital multinacional y de una administración autonómica para recuperar tejido industrial gra-

${ }^{74}$ RedesTelecom, 29 de octubre 2001; López et al., 2002.

75 Testimonio de Javier Larrucea.

76 Entrevista del autor a José Miguel de Diego Rodrigo, 7 de marzo de 2019; el ingeniero de Diego estuvo empleado dieciséis años en INDELEC durante las etapas de Philips y Ericsson. A partir de las instalaciones de Alonsotegi, P4Q abrió un centro de innovación en el Automotive Intelligence Center de Boroa y una fábrica en Estados Unidos-Alburquerque, Nuevo México; tiene asimismo una oficina de ventas en Madrid y exporta a más de una docena de países por todo el mundo. A lo largo de 2019, planeó poner en marcha un nuevo centro productivo en Kunshan (China), en las proximidades de Shanghai, la capital económica de China: Deia, 23 de febrero de 2019. 
cias a la introducción de una tecnología de primera línea de innovación en una zona deprimida (País Vasco) durante y tras la reconversión industrial de los años iniciales de la década de 1980. El estudio pretende esclarecer aspectos relevantes de la historia empresarial y de la reconstrucción del impacto de las políticas reindustrializadoras en torno a sectores con gran valor añadido. La presencia de multinacionales y su transferencia errática de capital y tecnología añaden aún más valor a este caso. El artículo se enmarca en un escenario de transiciones varias: entrada de España en la Unión Europea, liberalización de las telecomunicaciones y el final del monopolio del servicio, junto al afianzamiento de un modelo territorial descentralizado. Su apoyatura intelectual radica en cualificados estudios sectoriales de carácter agregado mientras que metodológicamente presenta un relato desde la perspectiva de la historia empresarial. La evidencia empírica emana de fuentes tanto empresariales como de las diversas administraciones públicas, que permiten adentrarse en los entresijos de los procesos y constatar la complejidad de los mismos. En sustancia, el artículo traza la evolución de una empresa del sector TICs, en general, y de las comunicaciones particularmente, en el marco de la confluencia de las estrategias de las multinacionales y de la política industrial, incluida la de la propia operadora monopolista de telecomunicaciones. Del lado español, la estrategia detrás de la creación de INDELEC fue dotarse de tejido industrial capaz de suministrar los equipos necesarios para el despliegue de las redes «celulares» de telefonía móvil pública en España, y no tanto el de competir por otros mercados como el de los sistemas «trunking» de telefonía móvil privada ${ }^{77}$. El caso central analizado y los ejemplos aducidos muestran elementos diferenciales respecto a la estrategia seguida por las multinacionales en otras ocasiones. No es una aportación menor evidenciar la importancia, y la insuficiencia a la vez, de las políticas industriales de los países dependientes tecnológicamente, debido a la sumisión a las multinacionales, poseedoras de las tecnologías y del capital. Finalmente, el trabajo revela que la experiencia no se zanjó con un fracaso total, ya que tuvo un moderado efecto de spin-off, visible en la aparición de pequeñas empresas, alguna de ellas de gran dinamismo,

77 Sí reconocía abiertamente esa especialización el Presidente del consejo de administración de Telefónica de España, S.A. (Velázquez-Gaztelu Ruiz): Diario de Sesiones del Congreso, 20 de mayo de 1992, 18-Comisiones, p. 18. 
que, al menos en parte, permitieron capitalizar el know-how acumulado durante años en la telefonía móvil.

En definitiva, la aportación diferencial de este estudio con respecto a otros similares radica en su perspectiva empresarial y en su enfoque comparativo, a la vez que en la combinación de elementos de regulación, de política industrial y de estrategias empresariales emanadas de agentes institucionales diversos. Sin duda, el acceso a nuevas fuentes y la disponibilidad de documentación vetada hasta el momento permitirán en el futuro ahondar en diversos aspectos, tales como las relaciones entre las multinacionales y las administraciones públicas o entre las multinacionales y la filial, sin olvidar las formas intraempresariales de transferencia de tecnología.

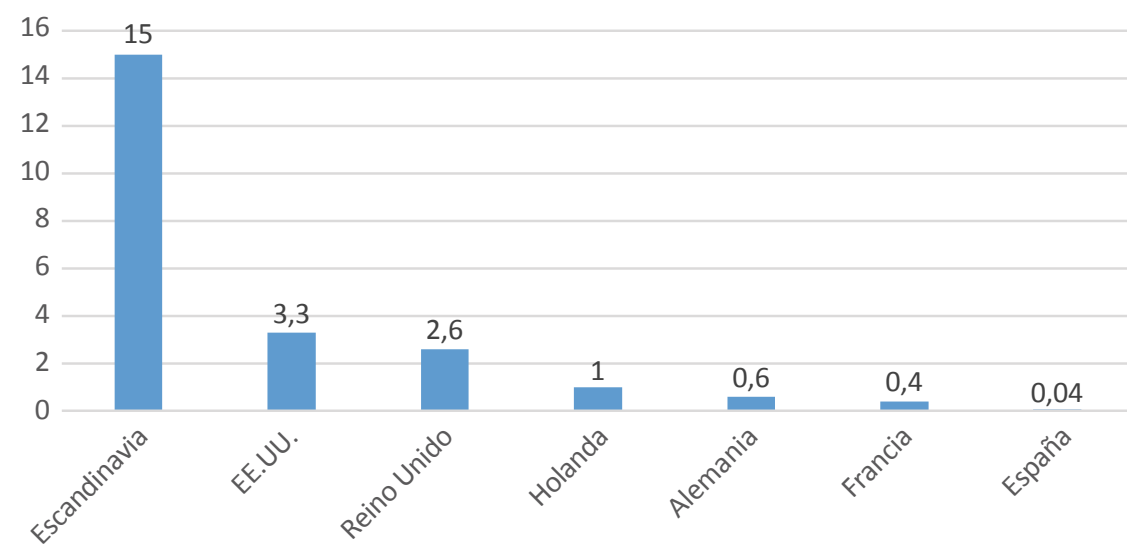

Anexo 1

Teléfonos de coche en un grupo de países industrializados.

Tasa de penetración por $1.000 \mathrm{~h}$

Fuente: elaboración propia a partir de Ministère des PTT (1987) y CTNE, Memoria anual 1987 


\section{Glosario}

Espectro radioeléctrico: se define como un recurso natural limitado, compuesto por todas las ondas radioeléctricas (en bandas de frecuencia entre $9 \mathrm{KHz}$ y $3000 \mathrm{GHz}$ ) que se propagan a través del espacio sin la necesidad de una guía artificial.

Estándar: lenguaje común que permite interoperar a múltiples sistemas desarrollados independientemente por distintos fabricantes. En la definición de la ISO, un estándar de telecomunicaciones es un conjunto de normas y recomendaciones técnicas que rigen la transmisión en los diferentes sistemas de comunicaciones.

GSM (Global Standard for Mobile communications): un estándar de teléfono móvil digital de segunda generación $(2 \mathrm{G})$ y el estándar de facto utilizado en Europa. Se implementa en las bandas de frecuencia de 800, 900, 1.800 y 1.900MHZ. La frecuencia más común utilizada es 900MHZ, seguida de 1.800MHZ.

Microprocesador: cerebro del ordenador diseñado para ejecutar los programas a partir de instrucciones y operaciones lógicas simples. Consiste en un chip, un tipo de componente electrónico en cuyo interior existen miles (o millones) de dispositivos electrónicos llamados transistores.

Módulos SMD (Surface Mount Devices): dispositivos electrónicos de montaje superficial cuyos componentes se montan en la superficie de la placa de circuito impreso (PCB) y que se utiliza para la fabricación de placas de circuito electrónico según una tecnología que permite el uso de ambos lados de una PCB.

Nordic Mobile Telephone (NMT): sistema «celular» de telefonía móvil pública, basado en el concepto teórico de la radiocomunicación celular, concebido por D. H. Ring en 1947 y que había desarrollado la AT\&T durante la década de 1970 .

Mensáfono: dispositivo sencillo usado en el servicio mensafónico o de radiobúsqueda por el que se transmiten mensajes unidireccionales procedentes de la red telefónica conmutada hacia abonados con ubicación móvil, que empezó a comercializarse en España en 1973 (Pérez Yuste).

Radiobúsqueda: según la ITU, sistema unidireccional de señalización selectiva y sin transmisión de palabra, concebido como prolongación de la red telefónica; sus principales modos de explotación son la llamada automática a un terminal común, las llamadas automáticas con señalización secundaria de audiofrecuencia y las llamadas de radiobúsqueda a través de una operadora de telefonía móvil.

Secráfono: dispositivo que transpone o invierte señales o codifica un mensaje en el transmisor para hacer que sea ininteligible en un receptor que no esté equipado con un dispositivo de descifrado configurado adecuadamente. 
Telefonía móvil: se basa en diferentes sistemas o estándares, cada uno con su propio protocolo o idioma; comprende redes de acceso, una red central, elementos del sistema y arquitectura de red.

Total Access Communications System (TACS), sistema analógico de telefonía celular implementado principalmente en Europa y modelado a partir del sistema AMPS en los Estados Unidos. En el Reino Unido, ETACS (TACS extendido) transmitía en la banda 871-904 / 916-949 MHz. El TACS de banda estrecha (NTACS) usó la banda 860-870 / 915-925 MHz.

Trunking: radiocomunicaciones móviles terrestres en grupos cerrados de usuarios usadas entre vehículos de transporte en general u otros más específicos (radiotaxis, compañías de seguridad o ambulancias).

UMTS (Universal Mobile Telecommunications Service): un estándar 3G que permite un rendimiento de datos teórico de hasta 2 Mbps.

Videotex: aplicación interactiva capaz de difundir, a través de una red de telecomunicación, información de forma paginada servida por un sistema informático y visualizada sobre un terminal y una línea telefónica.

\section{Fuentes primarias}

Assemblée Nationale de la France.

Comisión Nacional de Mercado de Valores.

Parlamento Vasco.

Registro Mercantil de Bizkaia.

Telefónica.

\section{Fuente oral}

Conversación del autor con Luis Solana Madariaga, Madrid, 8 de marzo de 2016. Entrevista del autor a José Miguel de Diego Rodrigo, 7 de marzo de 2019.

\section{Hemeroteca}

$A B C$.

Boletín Oficial del Parlamento Vasco.

Computer Business Review.

Computer World.

El País.

La Vanguardia. 
PCWorld.

Telecompaper.

PCWorld.

Wireless Cellular Monthly Newsletter.

\section{Referencias}

AYRES, Robert U., The Bubble Economy: Is Sustainable Growth Possible?, MIT Press, Cambridge MAS, 2014.

BEKKERS, Rudi, Mobile Telecommunications Standards: GSM, UMTS, TETRA, and ERMES, Artech House, Boston, 2001.

BOUCHER, Neil J., The Paging Technology Handbook, John Wiley \& Sons, Mendocino CA, 1992.

CALVO, Ángel, Telecomunicaciones y el nuevo mundo digital en España: la aportación de Standard Eléctrica, Ariel/Fundación Telefónica, Barcelona, 2014.

CALVO, Ángel, Historia de Telefónica: 1976-2000. Las telecomunicaciones en la España democrática, Ariel/Fundación Telefónica, Barcelona, 2016.

CALVO, Ángel, «Multinacionales, Estado y empresa semipública en la industria de tecnología avanzada durante la década de 1980», Investigaciones de Historia Económica-Economic History Research, 13, 2017, pp. 51-62.

CALVO, Ángel, «Technological change, opening and internationalization of Spanish telecommunications. The transition to the third generation of mobile telephony», Harvard Deusto Business Research, VIII, 1, junio, 2019, pp. 3-30. https://doi.org/10.3926/hdbr.196

CALZADA, J. y ESTRUCH, A., «Telefonía móvil en España: regulación y resultados», Cuadernos Económicos de ICE, 81, pp. 39-69.

CASTELLS, M., Nuevas tecnologías, economía y sociedad en España, volumen 1, Alianza, Madrid, 1986.

CASTELLS, M. et al., Mobile Communication and Society: A Global Perspective, MIT Press, Cambridge MA, 2009.

CASTILLO, Jaime del, «La política industrial del gobierno vasco», Ekonomiaz, 7-8, 1987, pp. 129-155.

CDTI, Memoria, Ministerio de Industria, Comercio y Turismo, Madrid, 1990.

CORRAL, A., Nuevas tecnologías de la información en el País Vasco, Ekonomiaz, 22, 1992, pp. 166-186.

DÍAZ, R., Inversión Extranjera Directa en España: Patrón de localización regional, Universidad de Vigo, Vigo, 2001.

DIRECTION DES TÉLÉCOMMUNICATIONS DES RÉSEAUX EXTÉRIEURS, Téléphone de voiture, Hemmerlé et Petit, París, 1983. 
Ángel Calvo

ERICSSON, Annual Report 1996, 1996.

ERNST \& YOUNG, Informe de Auditoría, Cuentas anuales e informe de gestión de la SPRI, Ernst \& Young, Bilbao, 2008.

EUROPEAN COMMUNITIES COMMISSION, Strategic Partnering and Local Employment Initiatives: A Report to the EEC Task Force for Small and Medium Enterprises, Office for Official Publications of the European Communities, Luxemburgo, 1989.

FERNÁNDEZ DE SANTOS, Federico, Ingemar Naeve, la anticipación y planificación como claves del éxito, Executive Excellence, 71, junio, 2010, pp. 30-35.

FERNÁNDEZ, C. y GONZÁLEZ, A., «Experiencias y realizaciones», Telos, 29, marzo-mayo de 1992, pp. 1-15.

GIL, Olga, Telecomunicaciones y política en Estados Unidos y España (18752002).Construyendo mercados, Centro de Investigaciones Sociológicas, Madrid, 2002.

GOBIERNO VASCO, La acción exterior del país vasco (1980-2003), Instituto Vasco de Administración Pública, Oñati, 2004.

GRAU, J., «La arquitectura de Telecomunicaciones de la XXV Olimpiada», Bit, enero-febrero de 1992, 74, pp. 63-67.

GUILLÉN, Mauro F., El auge de la empresa multinacional española, Madrid, Marcial Pons-Fundación Rafael del Pino, 2006.

IGI, Idea Group Inc., Enterprise Information Systems: Concepts, Methodologies, Tools and Applications: Concepts, Methodologies, Tools and Applications, Management Association, Information Resources, Idea Group Inc., Hershey PA, 2010.

INDELEC, Informe anual 1986, 1986.

LIAO, Hailin, «ICT as a general-purpose technology: The productivity of ICT in the United States revisited», Information Economics and Policy, 36, septiembre, 2016, pp. 10-25.

LÓPEZ, Santiago et al., Colaboración bajo incertidumbre: la formación de un grupo tecnológico en el sector de las telecomunicaciones, Economía Industrial, 346, 2002, pp. 81-96.

LÓPEZ GARCÍA, Santiago y VALDALISO, Jesús M. ${ }^{a}$, «Del acero y el cobre al silicio, del mercado nacional al mercado mundial. Orígenes y evolución de GAIA, el cluster de las TICS en el País Vasco», IX Congreso de la Asociación Española de Historia Económica, Murcia, 9-12 de septiembre de 2008.

LÓPEZ GARCÍA, S. y VALDALISO, Jesús M. ${ }^{a}$, Del acero y el cobre al silicio, del mercado nacional al mercado mundial. Orígenes y evolución de GAIA, el cluster de las TICS en el País Vasco, en CATALÁN, Jordi, MIRANDA, José Antonio y RAMÓN, Ramón, Distritos y clusters en la Europa del Sur, LID Editorial, Madrid, 2011, pp. 317-336. 
MARTÍ-RECOBER, M. et al. Llibre Blanc sobre les Telecomunicacions a Catalunya, Vol, I y II, Departament d'Indústria i Energía de la Generalitat de Catalunya y Telefónica, Barcelona, 1991.

MEURLING, John y Jeans, Richard, The Ericsson Chronicle: 125 Years in Telecommunications, Informationsforlaget, Estocolmo, 2000.

MINISTERIO DE INDUSTRIA Y ENERGÍA, Informe sobre la industria española, Volumen 2, Ministerio de Industria y Energía, Madrid, 1996.

MORENO, J., Bilbao: Declive industrial, regeneración urbana y reactivación económica de un espacio metropolitano, Instituto Vasco de Administración Pública, Bilbao 2005.

OFICINA DE RADIOCOMUNICACIONES DE LA UNIÓN INTERNACIONAL DE TELECOMUNICACIONES, La UIT y las Radiocomunicaciones, UIT, Ginebra, 2010.

ONDATEGUI, Julio César, Los Parques Científicos y Tecnológicos en España: retos y oportunidades, Comunidad de Madrid, Madrid, 2001.

PÉREZ SANJUÁN, Olga (coord.), De las Señales de Humo a la Sociedad del Conocimiento, Foro Histórico de las Telecomunicaciones, Colegio Oficial de Ingenieros de Telecomunicación, Madrid, 2006.

PÉREZ YUSTE, Antonio, «El proceso de implantación de la telefonía móvil en España», Antena del COITT, 9, 11 de septiembre de 2002, pp. 26-31.

PLAZA, María Beatriz, Política industrial de la Comunidad Autónoma del País Vasco. 1981-2001, Economía Industrial, 335/336, V-VI, 2000, pp. 2-16.

RÉGIE AUTONOME DES TRANSPORTS PARISIENS, Radiotéléphonie sur autobus, H. Dridé, París, 1984.

SÁNCHEZ REINÓN, Manuel, Redundancies and reorganisation at Ericsson and Siemens, European Monitoring Center on Change, Dublín, 2002.

SORET, Ignacio, «Los servicios de difusión en la LOT», Cuadernos de estrategia, 29, 1991, pp. 71-84.

TRIBUNAL VASCO DE CUENTAS PÚBLICAS, RESOLUCIÓN 44/1997 de 2 de junio, del Presidente del Tribunal Vasco de Cuentas Públicas, por la que se hace público el Informe sobre préstamos y ayudas concedidas por SPRI, S.A., Boletín Oficial del Parlamento Vasco, 1997152, 12 de agosto de 1997.

VALDALISO, Jesús M. a y LÓPEZ, Santiago, Personas innovando. La industria de las tecnologías electrónicas y de la información, Gaia. 1983-2008, Gaia, San Sebastián, 2008.

VERGARA, Miguel y HUIDOBRO, José Manuel, Las tecnologías que cambiaron la historia, Ariel, Madrid, 2016.

VV.AA., La economía del País Vasco: diagnóstico estratégico, Servicio de Estudios, Servicio de Estudios de La Caixa, Barcelona, 2010.

VV.AA., Ericsson en España. Una historia de éxito, valores y personas, Planeta, Barcelona, 2015. 
VV.AA., Las Claves del Éxito. Impactos sociales, deportivos, económicos y comunicativos de Barcelona'92, Centro de Estudios Olímpicos y del Deporte, Barcelona, 1996.

\section{Agradecimientos}

Esta investigación se adscribe al Centre d'Estudis 'Antoni de Capmany' d'Economia i Història Econòmica del Departament de Història i Institucions Econòmiques, Facultat d'Economia i Empresa (Universitat de Barcelona). Agradezco a sus responsables el apoyo que prestan a mi labor. Son asimismo acreedores de mi agradecimiento Francisco Lacha, que me ha cedido documentos imprescindibles para el conocimiento de la empresa estudiada, y José Miguel de Diego Rodrigo, por la comunicación de datos importantes y por su labor de intermediación. Finalmente, debo agradecer al editor de esta revista su hospitalidad y a los revisores anónimos del manuscrito su meticulosa labor.

\section{Datos del autor}

Ángel Calvo (angel.calvo@ub.edu) es doctor en Historia y profesor honorífico en la Universidad de Barcelona. Ha publicado numerosos libros -entre ellos la Historia de Telefónica en dos volúmenes-, y artículos en revistas nacionales e internacionales de reconocido prestigio. Sus líneas de investigación se centran en las telecomunicaciones, la transferencia de tecnología y la historia empresarial e industrial. También destaca su trabajo como director de tesis, revisor de trabajos para revistas nacionales e internacionales y asesor de medios de comunicación sobre temas de telecomunicaciones. Ha sido miembro del Consejo de la Societat Catalana d'Història de la Ciència i de la Tècnica desde su fundación y pertenece a varios grupos y asociaciones internacionales, como la vinculada a la European Science Foundation, el International Institute of Social and Economic Sciences, la Eurasia Business and Economics Society y la Sociedad Española de Historia Económica. 